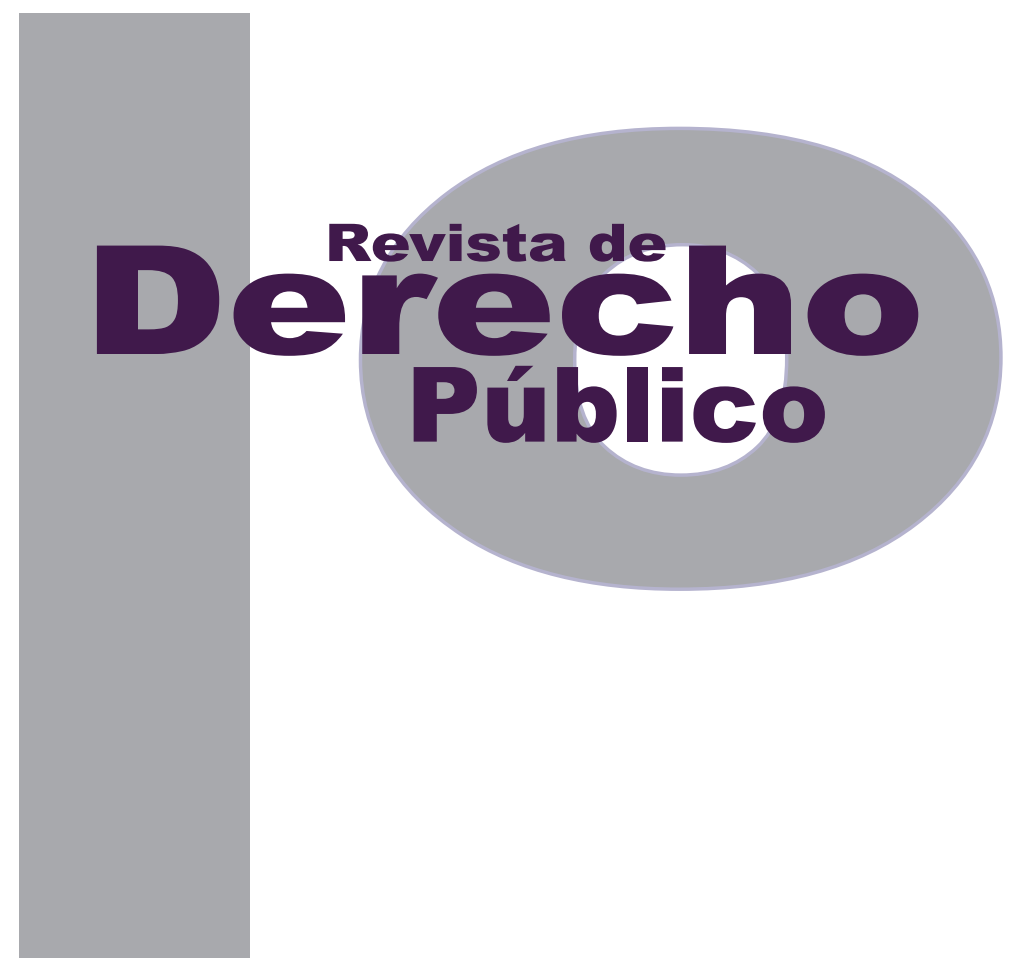

\title{
LOS MECANISMOS DE SUPERVISIÓN Y GARANTÍA DE LOS DERECHOS ECONÓMICOS, SOCIALES Y CULTURALES EN EL SISTEMA EUROPEO DE DERECHOS HUMANOS Y EL SISTEMA INTERAMERICANO DE DERECHOS HuMANOS
}

LAURA ROMERO VILLAMIZAR

Universidad de los Andes

Facultad de Derecho

Revista de Derecho Público N. ${ }^{\circ} 30$

Enero - Junio de 2013. ISSN 1909-7778 


\title{
Los mecanismos de supervisión y garantía de los derechos económicos, sociales y culturales en el Sistema Europeo de Derechos Humanos y el Sistema Interamericano de Derechos Humanos
}

\author{
Laura Romero Villamizar*
}

\begin{abstract}
RESUMEN
A pesar del reconocimiento internacional de la indivisibilidad e interdependencia de los derechos humanos, los derechos económicos, sociales y culturales (DESC) no cuentan con los mismos mecanismos de protección que los derechos civiles y políticos. Este artículo analiza, de manera comparativa, en el Sistema Europeo de Derechos Humanos y el Sistema Interamericano de Derechos Humanos los mecanismos de supervisión y garantía de los DESc a través del análisis del carácter jurídico de las normas que los consagran, los mecanismos directos para dar seguimiento a su cumplimiento o alegar su violación, y, finalmente, los pronunciamientos en los que el máximo tribunal en cada uno de estos sistemas avanza hacia la justiciabilidad de los DESC.
\end{abstract}

\begin{abstract}
The international community has long since recognized the indivisibility and interdependence of human rights. However, economic, social and cultural rights are not protected under the same mechanisms than civil and political rights. The article examines and compares the protection of ESCR in the European System of Human Rights and the Inter-American System of Human Rights. The analysis includes the legal nature of the ESCR standards, the mechanisms to monitor compliance and claim violations, and the steps taken by the European Court and the Inter-American court towards the justiciability of ESCR.
\end{abstract}

KEY WORDS: Economic, social and cultural rights, Justiciability,Supervision and enforcement, Inter-American Human Rights System, Protocol of 
Palabras Clave: derechos económicos, sociales y culturales; justiciabilidad, mecanismos de supervisión y garantía, Sistema Interamericano de Derechos Humanos, Protocolo de San Salvador, Sistema Europeo de Derechos Humanos, Carta Social Europea, Comité Europeo de Derechos Sociales.
San Salvador, European Human Rights System, European Social Charter, European Committee for Social Rights. 


\section{SUMARIO}

Introducción - I. NORMATIVIDAD - A. Sistema Europeo de Derechos Humanos: Ia Carta Social Europea B. Sistema Interamericano de Derechos Humanos: artículo 26 de la CADH y Protocolo de San Salvador - C. Relación comparativa de la normativa de DESC en el SEDH y el SIDH - II. MECANISMOS DE PROTECCIÓN A. Vía directa - 1. Sistema Europeo de Derechos Humanos: sistema de reportes y reclamaciones colectivas - 1.1. Reportes - 1.2. Reclamaciones colectivas - 2. Sistema Interamericano de Derechos Humanos: artículo $26 \mathrm{CADH}$ y artículo 19 PSS - 3. Relación comparativa de los mecanismos directos de protección de DESC en el SEDH y en el SIDH - B. Vía indirecta - 1. Sistema Europeo de Derechos Humanos: jurisprudencia Corte EDH - 1.1. Protección de los DESC con base en la prohibición de tortura y de tratos crueles, inhumanos y degradantes - 1.2. Protección de los DESC con base en el principio de no discriminación 1.3. Correlación entre la CSEy el CEDH - 2. Sistema Interamericano de Derechos Humanos: protección de IOS DESC a través de los derechos civiles y políticos - 2.1. Vida digna - 2.2. Derecho a la propiedad - 2.3. Libertad de asociación - 3. Relación comparativa de los mecanismos indirectos de protección de DESC en el SEDH y el SIDH - III. CONCLUSIONES - Bibliografía. 


\section{Introducción}

El reconocimiento de los derechos económicos, sociales y culturales (DESC) en el Derecho Internacional de los Derechos Humanos ha sido una conquista paulatina. Transcurrieron más de dos décadas de la Declaración Universal de Derechos Humanos (1948) antes de que la comunidad internacional reconociera que, al igual que los derechos civiles y políticos, los DESC constituyen derechos inalienables del individuo y no meros objetivos de política estatal. No obstante, la superación de la dicotomía entre las "generaciones" de derechos ${ }^{1}$ tiene todavía un camino por recorrer.

Si bien desde la I Conferencia de Derechos Humanos (Teherán, 1968) se ha reconocido la interdependencia e indivisibilidad entre los derechos civiles y políticos y los DESc, los sistemas de protección (a nivel global y regional) aún presentan en su normativa sustancial y procedimental rezagos de esta diferenciación, lo que resulta en obstáculos para su exigibilidad. A pesar del consenso internacional sobre la relevancia jurídica y el carácter vinculante de los DESc, su garantía

1 La consolidación normativa de los derechos humanos hizo inicialmente la distinción entre derechos de "primera generación" y derechos de "segunda generación". Los derechos de primera generación, que corresponden a los derechos civiles y políticos, fueron entendidos como aquellas libertades respecto de las cuales la obligación de garantía de los Estados exigía exclusivamente la abstención de injerencia. Los derechos de segunda generación, que corresponden a los DESC, fueron definidos como aquellos que realizan la igualdad material y precisan la intervención activa y fuerte de los Estados. Esta distinción doctrinaria fue eliminada al reconocer la interdependencia de los derechos humanos y el hecho de que respecto de ambas generaciones de derechos se requieren ambos tipos de comportamientos por parte del Estado. ETXEBERRIA, Xabier. Fundamentación y orientación ética de la protección de los derechos humanos. En: GÓMEZ ISA, Felipe; PUREZA, José Manuel. La protección internacional de los derechos humanos en los albores del siglo XXI. Humanitarian Net. Universidad de Bilbao. Bilbao, 2004. es, en muchos casos, una quimera para sus titulares.

Este trabajo tiene como objetivo estudiar las normas, instituciones y mecanismos (directos e indirectos) a partir de los cuales se puede exigir a los Estados el respeto y protección de los DESC en dos sistemas internacionales de protección de derechos humanos de carácter regional: el Sistema Europeo de Derechos Humanos (SEDH) y el Sistema Interamericano de Derechos Humanos (SIDH). Este análisis permitirá realizar una comparación de las reservas o avances al interior de cada sistema para que la indivisibilidad e interdependencia de los derechos civiles y políticos y los DEsc se traduzca en una correspondiente "indivisibilidad” de garantías.

La comparación de estos dos sistemas es pertinente y relevante en tanto se trata de los sistemas regionales con más trayectoria. A través de su normativa y jurisprudencia han logrado, en sus respectivas regiones, consolidar un sistema de responsabilidad estatal frente a la protección de derechos humanos, que ha tenido incidencia en las políticas de los Estados miembros y sus legislaciones.

El trabajo se estructura así: primero, se estudiarán las normas que consagran DEsc en cada sistema, haciendo énfasis en su naturaleza jurídica, carácter vinculante y en las obligaciones que imponen a los Estados. En segundo lugar se estudiarán los mecanismos de protección en cada sistema. Este capítulo se dividirá en el estudio de los mecanismos de protección directa, es decir, los mecanismos diseñados para exigir o regular la observancia de los DESc contenidos 
en las normas estudiadas en el capítulo precedente; y en el examen de la protección indirecta, teniendo en cuenta cómo el máximo órgano jurisdiccional en cada uno de estos sistemas se ha aventurado a la protección de los DESC a través de normas diferentes a aquellas que los consagran. Finalmente, se presentarán las conclusiones de este estudio.

\section{NORMATIVIDAD}

\section{A. Sistema Europeo de Derechos Humanos: Ia Carta Social Europea}

En el SEDH, la Carta Social Europea (CSE) es el punto de referencia para el desarrollo de lOS DESC. ES un instrumento jurídico para la creación de parámetros que garanticen un adecuado nivel de vida y un mínimo de protección social, constituyendo el marco del proyecto de solidaridad y justicia social europeo ${ }^{2}$. La cSE fue adoptada por el Consejo de Ministros del Consejo de Europa en 1961, dado que la Convención Europea de Derechos Humanos (CEDH) contempla únicamente el reconocimiento y protección de los derechos civiles y políticos y no el de los derechos económicos, sociales y culturales, que ya eran reconocidos como fundamentales en la Declaración Universal de los Derechos del Hombre $(1948)^{3}$.

2 BONET PÉREZ, Jordi; BONDÍA GARCíA, David. La Carta Social Europea. En: GÓMEZ ISA, Felipe; PUREZA, José Manuel. La protección internacional de los Derechos Humanos en los albores del siglo XXI. Humanitarian Net. Universidad de Bilbao. Bilbao, 2004. P. 442.

3 El artículo 22 de la Declaración Universal de los Derechos Humanos reconoce el derecho de toda persona a la seguridad social y a la satisfacción de los derechos económicos, sociales y culturales, indispensables a su dignidad y al libre desarrollo de su personalidad. Adicionalmente, el artículo 25 consagra el derecho a un nivel de vida adecuado que garantice la salud y el bienestar a través de la alimentación, el vestido, la vivienda, la asistencia médica y los servicios sociales ne-
El proceso de negociación que dio lugar a la adopción de la CSE se caracteriza por tensiones que enfrentaban a naciones a favor de una protección social elevada y a naciones que proponían un nivel de exigencia inferior ${ }^{4}$. En consecuencia, aunque la cSE es un texto que desarrolla un catálogo completo de derechos, reconoce la posibilidad de aceptación parcial de sus disposiciones en función de la evolución del contexto económico, del nivel de riqueza de cada Estado y de las singularidades de sus contextos sociales ${ }^{5}$. En este sentido, vemos cómo aún cuando la CSE constituye un avance jurídico en el reconocimiento de los DESc, hay ciertos aspectos que ponen en tela de juicio la exigibilidad general de estos en el SEDH.

La CSE, en su versión revisada de 1996, se compone de un preámbulo, cinco partes y un anexo. El preámbulo define los objetivos de la CSE: disfrute de los derechos sociales sin discriminación, mejoramiento del nivel de vida de los ciudadanos de los Estados contratantes y promoción de su bienestar. En la Parte I se incluyen los principios fundamentales de la CSE, que vinculan a los Estados, fijando unas metas a seguir y estableciendo que los contratantes no pueden adoptar medidas legislativas o administrativas que les sean contrarias. La Parte II enumera todos los derechos garantizados por este tratado interna-

cesarios; el derecho a seguros en caso de desempleo, enfermedad, invalidez, viudez, vejez u otros casos de pérdida de sus medios de subsistencia; y, finalmente, el derecho de cuidado especial para la maternidad y la infancia. BONET PÉREZ, Jordi; BONDía GARCIA, David. La Carta Social Europea. En: GÓMEZ ISA, Felipe; PUREZA, José Manuel. La protección internacional de los derechos humanos en los albores del siglo XXI. Humanitarian Net. Universidad de Bilbao. Bilbao, 2004. P. 443

$5 \quad$ Ibid 
cional, de carácter individual y colectivo; precisa el reconocimiento de determinados derechos y el establecimiento de singulares medidas de protección para trabajadores y empleadores, trabajadores migrantes, niños y adolescentes, la familia, la mujer trabajadora o madre y para los nacionales de los Estados parte. La Parte III consagra las obligaciones de los Estados para la garantía de los derechos reconocidos. La Parte IV establece mecanismos de control de la CSE. La Parte $\mathrm{V}$ recoge las cláusulas finales del tratado y las disposiciones sobre las derogaciones en caso de guerra u otro peligro público que amenace la nación. Finalmente, en el anexo a la CSE se encuentra la interpretación que debe darse a ciertas disposiciones, además de una definición del alcance de este instrumento respecto a las personas protegidas.

La CSE presenta un carácter dinámico, es un instrumento jurídico que se ha enriquecido y adaptado a las circunstancias a través de sucesivas modificaciones $^{6}$. No se puede perder de vista que la CSE está integrada por el texto de 1961 y por varios protocolos: el adicional de mayo de 1988, en donde se amplía el número de derechos reconocidos; el de enmienda de octubre de 1991, que reforma el sistema de garantía; el adicional de noviembre de 1995 que establece un sistema de reclamaciones colectivas y la CSE revisada en 1996.

Así, la Carta no solamente contiene los derechos tradicionalmente asociados con la protección so-

6 BONET PÉREZ, Jordi; BONdÍA GARCíA, David. La Carta Social Europea. En: GÓMEZ ISA, Felipe; PUREZA, José Manuel. La protección internacional de los derechos humanos en los albores del siglo XXI. Humanitarian Net. Universidad de Bilbao. Bilbao, 2004. P. 442 cial, como los derechos de los trabajadores y la seguridad social, sino que además la revisión de la Carta en 1996 permitió la introducción de nuevos derechos, lo que evidencia que la CSE ha sido receptiva a la evolución de los derechos sociales y ha sido progresista en cuanto al reconocimiento y la ampliación del contenido de los DESC? ${ }^{7}$.

No obstante, frente a los elementos que limitan la exigibilidad, encontramos lo que algunos doctrinantes han entendido como la elección "a la carta" de los derechos humanos reconocidos ${ }^{8}$. De conformidad con el artículo A de la Parte III de la CSE, los Estados parte tienen la posibilidad de determinar de antemano y libremente los derechos a que están dispuestos a obligarse. Se configura un núcleo duro de derechos, compuesto por nueve artículos de la Parte II (artícuIos $1,5,6,7,12,13,16,19$ y 20), que todos los Estados deben reconocer y garantizar al ratificar la CSE. Los Estados deben, por lo menos, obligarse a seis de ellos. Asimismo deben aceptar un número suplementario de mínimo 16 artículos o 63 párrafos numerados.

Esta flexibilidad en la ratificación de los derechos acaba por tener efectos similares a los que se derivan de una reserva modificativa ${ }^{9}$, y resulcostA, Jean-Paul. La Déclaration universelle des droits de l'homme. Les droits économiques, sociaux et culturels en question.

8 DÍAZ BARRADO, C. M. La Carta Social Europea: un instrumento válido para el desarrollo de los derechos sociales en Europa. En: MARIÑO MEnÉndez, F. M. y feRnÁndez LIESA, C. Política social internacional y europea. Universidad Carlos III, Instituto Francisco de Vitoria, Cátedra Concepción Arenal, Ministerio de Trabajo y Asuntos Sociales. Madrid, 1996. P. 233.

9 BONET PÉREZ, Jordi; Bondía garcíA, David. La Carta Social Europea. En: GÓMEZ ISA, Felipe; PUREZA, José Manuel. La protección internacional de los derechos humanos en los albores del siglo XXI. Humanitarian Net. Universidad de Bilbao. Bilbao, 2004. P. 452 
ta en un sistema normativo que no es uniforme para los Estados, sino que, por el contrario, se caracteriza por la formación de una pluralidad de regímenes jurídicos. Si bien los Estados pueden realizar sus compromisos de acuerdo con su capacidad institucional y económica, y teniendo en cuenta las particularidades de su contexto nacional, se desdibuja el carácter general de los derechos sociales en Europa y se pone en tela de juicio la integridad de la CSE.

Igualmente, otra característica de la CSE que atenúa el compromiso de los Estados es la posibilidad de denunciar cualquier artículo o párrafo de la Parte $\mathrm{II}^{10}$. Aunque esta medida pretende facilitar la participación de los Estados y la obtención de su consentimiento, el costo es nuevamente el quebranto de la integridad y el contenido de la CSE $^{11}$. Las reglas que permiten flexibilidad a los Estados en la manera de prestar su consentimiento frente a la CSE se apartan de las reglas generales de los tratados de derechos humanos ${ }^{12}$.

10 CSE. Artículo M, párrafos 2 y 3.

11 DIAZ BARRADO, C. M. La Carta Social Europea: un instrumento válido para el desarrollo de los derechos sociales en Europa. En: MARIÑo MENÉNDEZ, F. M. y FERnÁndez LIESA, C. Política social internacional y europea. Universidad Carlos III, Instituto Francisco de Vitoria, Cátedra Concepción Arenal, Ministerio de Trabajo y Asuntos Sociales, Madrid, 1996. P. 252.

12 En la Observación General n. 24, el Comité de Derechos Humanos del Sistema Universal de Naciones Unidas señala que la regla de la Convención de Viena sobre el Derecho de los Tratados, según la cual las reservas deben respetar el objeto y fin de un tratado, debe aplicarse de manera más estricta. Esto en cuanto a que los tratados de derechos humanos son una categoría especial dentro de los tratados de derecho internacional. Por un lado, su objeto no supone la creación de derechos y obligaciones recíprocos para los Estados partes, sino beneficiar a las personas que se encuentran bajo su jurisdicción. Por otro lado, todos los artículos dentro de un tratado de derechos humanos y la relación entre ellos tienen vital importancia para garantizar los objetivos generales de protección a la persona humana.
No obstante, una característica específica de los derechos contenidos en la CSE es el hecho de que las disposiciones no ratificadas, de todas formas, constituirán los objetivos sociales que los Estados parte han de esforzarse por alcanzar. El artículo A, Parte III, dispone que cada Estado que ratifique la CSE se comprometa a considerar la Parte I "como una declaración de los objetivos que tratará de alcanzar por todos los medios adecuados". Así, por su sola existencia e incluso por las disposiciones no aceptadas, la CSE constituye un factor de progreso. Igualmente, de conformidad con el artículo 22, Parte IV, las Partes Contratantes remitirán al Secretario General del Consejo de Europa, a petición del Comité de Ministros, informes sobre las disposiciones de la Parte II de la Carta que aquellas no hubieren aceptado.

Aunado a ello, una característica importante de los derechos de la CSE es su realización progresiva y la prohibición de regresividad ${ }^{13}$. Esto se pone de manifiesto en la utilización en varios artículos de los términos promover o desarrollar, comportando así una acción continua de los Estados $^{14}$. Si bien para un sector doctrinal estas fórmulas expresan la voluntad de los Estados de no vincularse internacionalmente o de aceptar únicamente compromisos de alcance limitado ${ }^{15}$,

13 El artículo $\mathrm{G}$ de la parte $\mathrm{V}$ dispone que "los derechos y principios enunciados en la Parte I, una vez llevados a la práctica, no podrán ser objeto de restricciones o limitaciones que no estén especificadas en las Partes I y II (...)".

14

BONET PÉREZ, Jordi; BONDIA GARCIA, David. La Carta Social Europea. En: GÓMEZ ISA, Felipe; PUREZA, José Manuel. La protección internacional de los derechos humanos en los albores del siglo XXI. Humanitarian Net. Universidad de Bilbao. Bilbao, 2004. P. 450.

15 JIMENA QUESADA, Luis. Les systemes conventionnels de réclamations collectives: la pratique du Comité Européen des Droits Sociaux. 
estas normas implican directa o indirectamente mejoras continuas y el mantenimiento de los derechos adquiridos en el marco de lo que se ha denominado "progreso social".

\section{B. Sistema Interamericano de Derechos Humanos: artículo 26 de la CADH y Protocolo de San Salvador}

A diferencia del CEDH, la Convención Americana sobre Derechos Humanos (CADH), además de reconocer una amplia gama de derechos civiles y políticos, contiene una consagración explícita de protección de los DESC. Bajo el capítulo III de la CADH, "Derechos Económicos, Sociales y Culturales", se encuentra el artículo 26 que remite a las normas económicas, sociales y sobre educación, ciencia y cultura contenidas en la Carta de la OEA, consagrando la consecución progresiva de los derechos que se derivan de ellas. A pesar de que se trata del único artículo dentro de este capítulo, y que su título (“Desarrollo Progresivo”) y redacción han suscitado dudas frente a la exigibilidad de los DESc ${ }^{16}$, el artículo 26 de la CADH es un reconocimiento de los DESC en el instrumento jurídico principal y con mayor fuerza vinculante en el SIDH. Esto supone un paso importante en el reconocimiento de la indivisibilidad e interdependencia de los derechos humanos, borrando la antigua distinción entre los derechos civiles y políticos y los DESC.

El estándar contenido en el artículo consagra el compromiso de los Estados de "Iograr progresivamente la plena efectividad de los derechos"

16 GÓmEZ, Verónica. (2007). Economic, Social and Cultural Rights in the Inter-American System. Oxford University Press. En: Economic, Social and Cultural Rights in Action. Pp. 168-169. que se desprenden de las normas mencionadas, las cuales corresponden a las contenidas en el capítulo VII de la Carta de la OEA sobre “Desarrollo Integral". Las normas a las cuales se hace remisión tienen un carácter general y están formuladas como objetivos o líneas de conducta que los Estados deben seguir para alcanzar un orden social justo, sin que se haga de manera explícita una consagración de derechos o de obligaciones correlativas para ellos. Sin embargo, en este capítulo se hace mención a: bienestar material, salarios justos, oportunidades de empleo y condiciones de trabajo aceptables, derechos sindicales, de asociación colectiva y huelga, seguridad social, nutrición y vivienda adecuadas, educación y fomento de la ciencia y la cultura ${ }^{17}$.

La remisión que hace el artículo y el título que le fue asignado han ocasionado dificultades interpretativas, que llevan a afirmar que el artículo 26 no enumera derechos específicos que sean exigibles a título individual o que la progresividad de estos derechos no implica la justiciabilidad directa de los DESC ${ }^{18}$. Esta crítica puede ser contrarrestada si se tiene en cuenta que el artículo 26 eleva al rango de "derechos" Ios contenidos de las normas económicas, sociales y culturales a las cuales se hace alusión. Por otra parte, la progresividad en la consecución de la efectividad de los DESC no puede ser entendida como una exclusión de su justiciabilidad: se trata de una consagración normativa que simple-

17 Carta OEA. Artículos 30, 33, 34, 45, 47, 49, 50, 51 y 52.

18 MELISH, Tara J. (2007). Rethinking the "LESS AS MORE" Thesis: Supranational Litigation of Economic, Social and Cultural Rights in the Americas. P. 207. 
mente hace referencia a la manera en que los Estados deben cumplir las obligaciones correlativas a estos derechos ${ }^{19}$.

Precisamente, el obstáculo principal a la efectiva protección de los DESC en el SIDH recae en la identificación de las obligaciones legales que el artículo 26 impone a los Estados. Si bien existe una tendencia a entender que deben aplicarse diferentes estándares a los derechos consagrados en el capítulo III respecto de los del capítulo II, no se debe perder de vista que frente a los derechos del artículo 26 de la $\mathrm{CADH}$, son exigibles las obligaciones de respeto, garantía y adecuación del orden interno contenidas en los artículos 1 y 2 de la $\mathrm{CADH}^{20}$, además de la exigencia de "desarrollo progresivo".

Ahora, además de la inclusión expresa de los DESc en el cuerpo de la CADH, en el seno del SIDH se creó otro instrumento diseñado para el reconocimiento y protección de este tipo de derechos. En noviembre de 1988, en el marco de la XVIII Asamblea General de la OEA, se aprobó y firmó el Protocolo Adicional a la CADH sobre Derechos Económicos, Sociales y Culturales, "Protocolo de San Salvador" (PSS). Esto, con fundamento en el artículo 77 de la CADH que otorga a los Estados parte y a la Comisión Interamericana de Derechos Humanos (CIDH) la posibilidad de someter

19 La implementación progresiva supone la prohibición de adoptar legislación o medidas administrativas que reduzcan el nivel de protección alcanzado respecto de los DESC, al igual que la obligación de implementar actuaciones concretas encaminadas hacia la plena satisfacción de estos. ABRAMOVICH, Víctor; RossI, Julieta. La tutela de los derechos económicos, sociales y culturales. Revista de Estudios Socio-Jurídicos. Universidad del Rosario. Vol. 9, 2007. P. 41. tional Litigation of Economic, Social and Cultural Rights in the Americas. P. 262. a la Asamblea General de la OEA proyectos de protocolos adicionales, de tal manera que sea posible incluir de manera progresiva derechos adicionales en el sistema de protección.

La creación en 1988 del Protocolo Adicional a la CADH en materia de Derechos Económicos, Sociales y Culturales o Protocolo de San Salvador representó el punto culminante de una toma de conciencia, global y regional, a favor del reconocimiento internacional de loS DESC: se reconoce que ya no podían ser entendidos como simples objetos de la acción política de los Estados. El PSS surge entonces del intento de remediar las deficiencias de los DESC en el SIDH, reforzando su protección ${ }^{21}$.

El PSS avanza en la estructuración de los DESC en el artículo 26 de la CADH, al consagrar explícitamente su contenido. En su preámbulo se indica que "si bien los derechos económicos sociales y culturales fundamentales han sido reconocidos en anteriores instrumentos internacionales, tanto de ámbito universal como regional, resulta de gran importancia que éstos sean reafirmados, desarrollados, perfeccionados y protegidos". Aún cuando normas del pss disponen la justiciabilidad directa de algunos derechos -aspecto que será explicado en la sección de mecanismos de protección directa de los DESC-, es importante destacar que este instrumento tiene gran importancia en términos de interpretación de la CADH. Aunque el pSs sea posterior a la CADH, su carácter adicional a este instrumen-

21

CANCADO TRINDADE, Antonio Augusto. La protección internacional de los derechos económicos, sociales y culturales. En: Estudios de Derechos Humanos. Tomo I. 
to, el artículo 29 de la $\mathrm{CADH}^{22}$ y el concepto de corpus juris de los derechos humanos desarrollado por la Corte Interamericana de Derechos Humanos (Corte IDH) ${ }^{23}$ permitiría que el PSS sea utilizado para delimitar el contenido y alcance de los derechos en la $\mathrm{CADH}$, en este caso, del artículo 26. Así, el pSs no solamente tiene valor en sí mismo, sino que tiene incidencia en la aplicación de la CADH.

Respecto al contenido del pss, encontramos que las obligaciones estatales de protección y garantía de IOS DESC no tienen carácter absoluto ni inmediato. El artículo 1 del pss obliga a los Estados parte a adoptar medidas de orden interno y por medio de cooperación internacional "hasta el máximo de los recursos disponibles y teniendo en cuenta su nivel de desarrollo". Igualmente, la efectividad de los DESc aspira a ser obtenida "progresivamente y de acuerdo con la legislación interna”. El mismo artículo 1 plantea una nueva dicotomía entre los derechos reconocidos por el PSS, pues habla de DESC de "exigibilidad inmediata" y de "realización progresiva". Si bien el planteamiento de obligaciones estatales frente a derechos contenidos en el pss tiene la ventaja de permitir flexibilidad y margen de discrecionalidad a los Estados, garantizando estos

22 El artículo $29 \mathrm{CADH}$ contempla que ninguna de las disposiciones de la CADH podrá ser interpretada de tal modo que se limite el goce y ejercicio de cualquier derecho o libertad reconocido de acuerdo con las leyes de un Estado parte o de acuerdo con otra convención en que este sea parte (literal b) o de forma que se excluyan otros derechos y garantías inherentes al ser humano (...)

23 La Corte IDH ha sostenido que los derechos de la CADH deben ser entendidos conforme al corpus juris internacional en el cual esta se enmarca, el cual comprende las normas fundamentales contenidas en otros instrumentos internacionales relacionados con la protección de los derechos humanos y las decisiones de órganos con esta misma función. Corte IDH, Caso de los "Niños de la Calle" (Villagrán Morales). Sentencia de 19 de noviembre de 1999. Serie C. No. 64. Párr. 194. derechos de acuerdo con las posibilidades de su orden económico y social, es necesario tener en cuenta que se dificulta la exigibilidad por falta de criterios o pautas claras para determinar el cumplimiento.

En el plano sustantivo, el PSs se inspira en el Pacto Internacional de Derechos Económicos, Sociales y Culturales y replica algunas de sus disposiciones de manera idéntica. El Pss consagra el derecho al trabajo (artículo 6), a las condiciones de trabajo justas (artículo 8), a la seguridad social (artículo 9), a la salud (artículo 10), a un medio ambiente sano (artículo 11), a la alimentación (artículo 12), a la educación (artículo 13), a los beneficios de la cultura (artículo 14), a la constitución y protección de la familia (artículo 15), del niño (artículo 16), los ancianos (artículo 17) y los minusválidos (artículo 18). Además, garantiza el dinamismo de los DESc pues en el artículo 22 se reconoce la incorporación de otros derechos o su ampliación.

Finalmente, la ratificación del pss se realiza respecto del instrumento en su conjunto y no únicamente frente a derechos específicos. Si bien los Estados podrán formular reservas sobre una o más disposiciones al ratificarlo, estas no deberán ser incompatibles con el objeto y el fin del Protocolo 24 .

\section{Relación comparativa de la normativa de DESC en el SEDH y el SIDH}

Teniendo en cuenta el análisis de las normas que reconocen IOS DESC en el SEDH y en el SIDH,

24 Protocolo de San Salvador. Artículo 20. 
encontramos que si bien no existen diferencias respecto al contenido de los derechos que se ha querido proteger, el carácter de estas en uno y otro sistema tiene distinta naturaleza y diferente fuerza jurídica vinculante. Mientras que en el SEDH el reconocimiento y estructuración de los DESC son un instrumento independiente (no una incorporación o adición al instrumento fundante de este sistema -CEDH-), en el SIDH los DESC son declarados en la misma CADH y desarrollados en un instrumento adicional a esta que busca complementarla. En este sentido, el SIDH ha dado pasos más decididos para la consagración normativa de los DESC y demuestra una iniciativa más contundente de crear normas con fuerza vinculante para los Estados parte que además articulen el sistema, de conformidad con los principios de indivisibilidad e interdependencia de los derechos humanos.

Adicionalmente, podría decirse que el SIDH va un paso adelante en el intento de desarrollar normas de DEsc con carácter vinculante si se tiene en cuenta que el pss (que contiene el catálogo preciso de DESC) debe ser ratificado en conjunto, a diferencia de la cSE que es flexible en la ratificación y denuncia. Esto pone de manifiesto cómo en el SIDH los DESC intentan ser normas jurídicas vinculantes, mientras que en el SEDH solo algunas normas obligan a los Estados y las demás son parámetros de conducta.

En ambos sistemas, las normas sobre DESc establecen obligaciones para los Estados parte de carácter progresivo. En el SEDH y en el SIDH Se reconoce que el contexto económico, recursos y nivel de desarrollo del Estado, al igual que las características del medio social, son un factor que determina la manera en la que los Estados cumplirán las obligaciones de DESC. Sin embargo, mientras que estas obligaciones en el SIDH se ven reforzadas por los deberes de respeto, garantía y adecuación del orden interno consagrados de manera general en los artículos 1 y 2 de la CADH, en el SEDH la regla general en la Parte III de la CSE reconoce los DESC como "objetivos que (el Estado) tratará de alcanzar por todos los medios adecuados", compromiso que se hace más estricto únicamente respecto de los derechos específicamente reconocidos por el Estado, sin que se precisen obligaciones más concretas.

\section{MECANISMOS DE PROTECCIÓN}

\section{A. Vía directa}

\section{Sistema Europeo de Derechos Huma-} nos: sistema de reportes y reclamaciones colectivas

Dado que la cSE no le atribuye jurisdicción a la Corte Europea de Derechos Humanos (Corte EDH), existen dos mecanismos para materializar la protección de los derechos allí contenidos: el sistema de reportes y el de reclamaciones colectivas, introducidos en la reforma de 1995. A continuación se analizarán sus características.

\subsection{Reportes}

Los artículos 21 a 29, de la Parte IV de la CSE, contemplan un mecanismo de supervisión no contencioso, basado en la obligación de los Estados parte de presentar informes periódicos 
sobre aplicación de las disposiciones de la CSE. En el análisis de estos informes, al igual que en la elaboración de conclusiones y recomendaciones, se ven involucrados tres órganos diferentes: el Comité Europeo de Derechos Sociales (CEDS), antes Comité de Expertos Independientes, que es un órgano técnico-jurídico compuesto por nueve miembros elegidos por la Asamblea Parlamentaria del Consejo de Europa, de una lista de expertos de máxima integridad y competencia reconocida en cuestiones sociales nacionales e internacionales ${ }^{25}$; el Comité Gubernamental, órgano político compuesto por un representante de cada una de las Partes Contratantes; y, el Comité de Ministros, órgano principal del Consejo de Europa, que reúne los representantes de los Estados miembros. Igualmente, el mecanismo de reportes permite la participación de sectores de la sociedad a través de organizaciones nacionales afiliadas a organizaciones internacionales y organizaciones internacionales no gubernamentales.

Los informes son públicos. De conformidad con los artículos 21 y 22 de la Parte IV de la CSE, deben ser presentados cada dos años respecto de disposiciones que el Estado parte haya aceptado y en intervalos apropiados, de acuerdo con la petición del Comité de Ministros del Consejo de Europa, respecto de las disposiciones que no haya aceptado. Desde 1992, en la práctica, la periodicidad de la presentación se ha dado

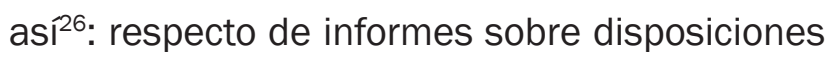

25 CSE. Parte IV. Artículo 25

26 BONET PÉREZ, Jordi; BONDÍA GARCíA, David. La Carta Social Europea. En: GÓMEZ ISA, Felipe; PUREZA, José Manuel. La protección internacional de los derechos humanos en los albores del siglo XXI. Humanitarian Net. Universidad de Bilbao. Bilbao, 2004. P. 463 aceptadas, la obligación de su presentación bienal se reserva para las disposiciones de la Parte Il de la cSE que son consideradas como el núcleo duro u obligaciones fundamentales de la CSE, mientras que para el resto de las disposiciones de la Parte II aceptadas por el Estado el informe será cuatrienal. En relación con la presentación de informes sobre disposiciones no aceptadas, respecto de los cuales el Comité de Ministros indica la periodicidad, se ha mostrado una tendencia a exigirlos sobre disposiciones que los Estados parte mayoritariamente no han aceptado. La diferenciación en los derechos de los que se exige presentación de informes pone en evidencia no solamente la graduación en el carácter vinculante de los DESc, como se explicó en la parte normativa, sino también la creación de una jerarquización de estos derechos en cuanto a sus garantías.

Una vez un Estado parte presenta un informe y antes que sea remitido al CEDS, podrán presentar observaciones sus organizaciones nacionales afiliadas a organizaciones internacionales de empleadores o trabajadores, y las organizaciones no gubernamentales con estatuto consultivo ante el Consejo de Europa, especialmente calificadas en materias reguladas por la cSE.

Posteriormente, el cEDS evaluará jurídicamente la conformidad de las legislaciones y prácticas nacionales con las obligaciones de la $\operatorname{csE}^{27}$. Tras un análisis que contempla nombramiento de relatores para cada disposición de la CSE examinada, así como la conformación de grupos de

27 CSE. Parte IV. Artículo 24. 
trabajo (cuatro o cinco miembros) para preparar las decisiones del plenario ${ }^{28}$, el CEDS presentará informe público con conclusiones finales. En el examen del reporte, el cEDS podrá pedir al Estado que lo presenta información o precisiones adicionales, y podrá convocar y mantener reuniones públicas con el Estado ${ }^{29}$.

Las conclusiones del CEDS son remitidas al Comité Gubernamental que se encarga de preparar el trabajo del Comité de Ministros. Sobre la base de las conclusiones del CEDS, selecciona de manera motivada las situaciones que deberían ser objeto de recomendación específica, de conformidad con argumentos de política social y económica. Asimismo, este Comité realiza propuestas de estudios sobre cuestiones sociales o sobre modificación de artículos de la CSE. Lo anterior pone de manifiesto cómo, en la práctica, las funciones del Comité Gubernamental resultan en que este órgano pueda filtrar las sugerencias del órgano técnico-jurídico con base en criterios políticos.

Finalmente, el Comité de Ministros adopta una resolución sobre el conjunto del ciclo de control efectuado y emite recomendaciones específicas dirigidas a los Estados, en caso de ser necesario. Las decisiones adoptadas no son jurídicamente vinculantes para el Estado parte afectado y, en la práctica, se ha evidenciado que la ausencia de una respuesta positiva de los Estados a estas no tiene mayor consecuencia que la

\footnotetext{
28 Reglas 16 y 17 del procedimiento ante el CEDS

29 CSE. Parte IV. Artículo 24.3.
}

constatación posterior de este hecho en la misma dinámica de supervisión ${ }^{30}$.

El sistema de reportes presenta como ventaja la exigencia al Estado de rendir cuentas sobre su gestión frente al cumplimiento de los DESc contenidos en la CSE. Encontramos, sin embargo, que las conclusiones finales sobre el estado de aplicación de los derechos contenidos en la CSE, al igual que las recomendaciones, pasa por un filtro político que comprende, tanto el Comité Gubernamental como el Comité de Ministros, apartándose de la apreciación estrictamente jurídica del CEDs. No obstante, vemos que la práctica del CEDS a través de informes públicos de los reportes es un referente conceptual importante respecto de la definición y alcance de los derechos contenidos en la CSE y de la naturaleza de las obligaciones que estos imponen a los Estados.

\subsection{Reclamaciones colectivas}

El mecanismo de reportes de la CSE fue complementado con el Protocolo Adicional de 1995, en el que se establece un sistema cuasi-contencioso de reclamaciones colectivas que tiene por objeto mejorar la aplicación efectiva de los derechos sociales contenidos en la $\mathrm{CSE}^{31}$. Este mecanismo se caracteriza por la participación de otros órganos del SEDH, las particularidades frente a la legitimación activa, y el carácter del proceso y la interpretación que se lleva a cabo, aspectos desarrollados a continuación.

30 Bonet PÉREZ, Jordi; BondíA GARCiA, David. La Carta Social Europea. En: GÓMEZ ISA, Felipe; PUREZA, José Manuel. La protección internacional de los derechos humanos en los albores del siglo XXI. Humanitarian Net. Universidad de Bilbao. Bilbao, 2004. P. 463

Protocolo 1995. Preámbulo. 
A través de una reclamación colectiva es posible alegar la aplicación no satisfactoria de cualquiera de los derechos contenidos en la cSE por parte de cualquier Estado que haya ratificado el Protocolo. Teniendo en cuenta que el examen legal de las reclamaciones colectivas es competencia del CEDS, este mecanismo refuerza las funciones de dicho órgano.

El resultado de la reclamación interpuesta es un informe con las conclusiones del cEDs sobre la compatibilidad de la actuación del Estado con la disposición objeto de la reclamación. En su decisión, el cEDs toma en cuenta las observaciones que, en virtud del artículo 7 del Protocolo, otros Estados parte y organizaciones internacionales de empleadores y de trabajadores realicen, ampliando así los criterios de decisión con la perspectiva de diferentes sectores de la sociedad europea.

El informe del cEDs es transmitido al Comité de Ministros del Consejo de Europa, que con base en él adoptará una resolución por mayoría de votos. Si el cEDs concluye que la aplicación de la CSE no ha sido satisfactoria, el Comité adoptará, por mayoría de dos tercios, una recomendación dirigida al Estado parte involucrado ${ }^{32}$, quedando este obligado a manifestar las medidas adoptadas en el siguiente ciclo en el que le corresponda presentar un informe ${ }^{33}$. Igualmente, el Comité podrá decidir, por mayoría de dos tercios de las Partes Contratantes de la CSE, consultar al Comité Gubernamental cuando el informe del

32 Protocolo Adicional de 1995 a la Carta Europea de Derechos Sociales. Artículo 9

33 Protocolo Adicional de 1995 a la Carta Europea de Derechos Sociales. Artículo 10.
CEDs plantee nuevas cuestiones.

En similar forma que en el mecanismo de reportes, el sistema de reclamaciones colectivas involucra una pluralidad de órganos del Consejo de Europa. Las conclusiones del CEDS, al igual que las recomendaciones específicas a los Estados, únicamente cobran relevancia jurídica al ser elevadas a una Resolución del Comité de Ministros, que puede ser asesorado por el Comité Gubernamental. En este sentido, vemos cómo el mecanismo de reclamaciones colectivas se basa no solamente en un análisis jurídico, sino también en el control político de los Estados miembros del Consejo de Europa.

Ahora, respecto de la legitimación activa, el carácter colectivo del recurso implica que solo las organizaciones contempladas en los artículos 1 y 2 del Protocolo Adicional de 1995 (y no los individuos) tienen la facultad de interponer las reclamaciones. Así, solamente las organizaciones internacionales y nacionales de trabajadores o empleadores, las organizaciones internacionales no gubernamentales (ONG) dotadas de estatus consultivo frente al Consejo de Europa e inscritas en la lista establecida para estos efectos, y las ong nacionales respecto de quienes un Estado parte haya manifestado explícitamente su consentimiento, podrán interponer las reclamaciones colectivas. Frente a la noción de “organizaciones nacionales" el cEDs ha adoptado un concepto autónomo en el que no corresponden estrictamente a aquellas que el Estado reconozca como tales en su legislación ${ }^{34}$. Se ha

34 Comité Europeo de Derechos Sociales. Reclamación 6/1999, Syndicat national des professions du tourisme c. Francia; Reclamación 10/2000 Tehy y STTK c. Finlandia. 
establecido que es necesario tomar en cuenta otros factores como el número de afiliados y el papel efectivo que puedan desempeñar en las negociaciones a escala nacional ${ }^{35}$. De cualquier forma, en ningún escenario un individuo detentará legitimación activa.

En lo que atañe a personas protegidas por este mecanismo, es decir, aquellos en favor de quienes se podría interponer la reclamación, la CSE contempla un criterio territorial. En su artículo 34, la Carta establece que los derechos allí consagrados serán reconocidos a toda persona que se encuentre en su territorio nacional ${ }^{36}$. Sin embargo, las reglas sobre la legitimación activa en las reclamaciones colectivas resultan en que el objeto de este mecanismo sea el cuestionamiento de las medidas estructurales de una política social que tengan un carácter general o que afecten a un gran número de personas ${ }^{37}$. El diseño de este mecanismo plantea la exigibilidad de lOS DESC desde la perspectiva de un derecho colectivo de reclamación, lo que deriva en que este sistema esté menos dado a la protección de derechos de personas individualizadas ${ }^{38}$.

35 Consejo de Europa. Informe explicativo del Protocolo de 1995 Adicional a la Carta Europea de Derechos Sociales. Párrafo 23. “ “

36 Las obligaciones de los Estados no se extienden a las personas extranjeras sino únicamente en la medida en que sean residentes de otras partes contratantes que vivan legalmente o trabajen regularmente en el territorio de la parte contratante interesada. Carta Social Europea. Anexo. Numeral 1.

37 SUDRE, F. "Le Protocole additionnel à la Charte Sociale Européenne prévoyant un système de réclamations collectives". Revue Générale de Droit International Public, 100, 1996, 3. P. 726-727.

38 QUINN, Gerard. "The legal status of the European Social Charter - Taking Interdependence and Indivisibility seriously". UNIDEM Seminar: "The status of International Treaties of Human Rights”. Octubre 2005. P. 7.
En relación con la competencia en razón de la materia, si bien todos los derechos de la CSE Son objeto de protección, solo puede hacerse una reclamación colectiva contra un Estado parte con respecto a las disposiciones que este haya ratificado. El CEDs ha reconocido que la aplicación de un derecho contemplado en la Carta no excluye la aplicación de otro y que, por el contrario, se puede realizar una aplicación conjunta de los derechos de la $\operatorname{cSE}^{39}$. Sin embargo, esta posición progresista del CEDS, en la que se reconoce la integridad de la cSE y el carácter complementario de los derechos allí reconocidos, encuentra como limitación la voluntad de los Estados de obligarse únicamente a algunos derechos de la CSE, lo cual es permitido gracias al enfoque "a la carta" de la cSE.

Ahora, encontramos que si bien las conclusiones del CEDS no son vinculantes y podrían entenderse más como soft law ${ }^{40}$, el carácter contencioso del procedimiento de reclamaciones colectivas

39 Este reconocimiento se presenta en la decisión de fondo sobre la reclamación 41 de 2007 - Centro de Defensa de Personas con Discapacidad Mental contra Bulgaria, en donde se realiza una aplicación combinada del artículo 15 (derechos de personas discapacitadas) y 17 (derecho de los menores y adolescentes a la protección social, jurídica y económica).

40 El término soft law es utilizado por la doctrina para describir principios, reglas, estándares o directrices que carecen de efecto vinculante, aunque tengan determinados efectos jurídicos como su utilización en la interpretación de normas o la creación de expectativas de comportamiento. Dentro de los criterios que se han utilizado para reconocer un instrumento como soft law, Christine Chinkin ha identificado: el hecho que haya sido formulado en términos no obligatorios de acuerdo con los procesos tradicionales de creación de derechos (tratados o costumbre), que procedan de órganos carentes de autoridad para crear normas internacionales, que permanezcan ajenos a cualquier teoría de la responsabilidad internacional y que se basen exclusivamente en la adhesión voluntaria y no exista un mecanismo jurídico para su exigencia. Este fenómeno comprende un amplio espectro de documentos internacionales, dentro de los que se encuentran las resoluciones, recomendaciones e informes adoptados por organismos internacionales. TORO HUERTA, Mauricio Iván del. El fenómeno del soft law y las nuevas perspectivas del derecho internacional. Curso DIP. 2007. UMAG. 
y el análisis e interpretación jurídicos a los que hay lugar le dan un respaldo a las conclusiones del CEDs. Por esto, aunque estas no puedan obligar a los Estados, sí son criterios interpretativos o pautas que determinan el cumplimiento.

El procedimiento de reclamaciones colectivas tiene carácter contencioso, en donde por decisión del CEDS, de oficio o a instancia de parte, se podrá llevar a cabo una audiencia contradictoria con participación de las partes y de todos los intervinientes a los que se autoriza a presentar observaciones por escrito. El proceso se rige por el principio de la buena administración de justicia (artículo 26 del Reglamento del CEDS) y es utilizado en algunas reclamaciones ${ }^{41}$.

Teniendo en cuenta que, de conformidad con el artículo $\mathrm{C}$ de la CSE al igual que con la parte III de su anexo, este instrumento contiene compromisos jurídicos de carácter internacional para los Estados, la función del cEDs es eminentemente de carácter jurídico: el Comité asume el rol de intérprete jurídico supremo de la CSE, en tanto en el marco del procedimiento de reclamaciones colectivas debe dictaminar si los Estados parte han respetado sus obligaciones en el escenario de la controversia planteada ${ }^{42}$. Así lo ha reconocido el CEDS, resaltando que "frente a la Carta, tanto en virtud de su texto inicial como de su versión modificada de 1996, le corresponde (al CEDS) dar una interpretación jurídica de las disposiciones de la Carta y pronunciarse

41 Comité Europeo de Derechos Sociales. COHRE V. Francia. Reclamación 58 de 2009; COHRE v. Italia. Reclamación 63 de 2010.

42 JIMENA QUESADA, Luis. Les systemes conventionnels de réclamations collectives: la pratique du Comité Européen des Droits Sociaux. con respecto a si la situación de los Estados es conforme a éstas" 43 . Igualmente, es de señalar que las decisiones del ceDs sobre una reclamación colectiva, en lo relativo a la admisibilidad y al asunto de fondo, se enmarcan en el respeto al principio jurídico de la motivación de las decisiones $^{44}$.

Además, las decisiones de fondo del ceDs presentan la misma estructura de las de la Corte EDH, incluida la posibilidad que los miembros del CEDS presenten opiniones disidentes ${ }^{45}$. La aproximación del CEDS a la CSE para determinar si se presentó una inobservancia de los derechos en ella reconocidos se realiza conforme a la metodología de interpretación jurídica, es decir, la interpretación de la Carta no es ajena a las reglas tradicionales de la hermenéutica jurídica: interpretación gramatical, lógica, sistemática, teleológica, histórica y contextual ${ }^{46}$. Todas contempladas en la Convención de Viena sobre Derecho de los Tratados. A modo de ejemplo, en la decisión de fondo de la reclamación de la Organización Mundial contra la Tortura (OMCT) vs. Irlanda, el Comité ilustra y pone en práctica estas modalidades de interpretación ${ }^{47}$.

43 Comité Europeo de Derechos Sociales. Reclamación n. 18 de 2003, Organización Mundial Contra la Tortura (OMCT) vs. Irlanda. Decisión de fondo. Diciembre 7 de 2004.

44 JIMENA QUESADA, Luis. Les systemes conventionnels de réclamations collectives: la pratique du Comité Européen des Droits Sociaux.

45 Ibid.

46 Ibid.

47 Comité Europeo de Derechos Sociales. Reclamación nº 18 de 2003, Organización Mundial Contra la Tortura (OMCT) vs. Irlanda. Decisión de fondo. Diciembre 7 de 2004. 
También, el carácter jurídico de la labor del cEDS en el marco de las reclamaciones colectivas se ve reforzado en el hecho de que este órgano realiza una interpretación sistemática, que tiene en cuenta otros tratados de derechos humanos, al igual que la actividad jurisprudencial de los órganos internacionales encargados de su aplicación. Por ello, a la hora de determinar la aplicación de la CSE en una situación concreta, no solamente se tiene en cuenta la actividad jurisdiccional de la Corte EDH, sino también la de órganos pertenecientes a la Organización de Naciones Unidas ${ }^{48}$. Esto con el fin de que los DESC reconocidos en la Carta sean interpretados de conformidad con los consensos internacionales existentes sobre su contenido y alcance.

Adicionalmente a la interpretación sistemática ad extra, se realiza también una interpretación sistemática ad intra ${ }^{49}$, pues el CEDS en aras de mantener la coherencia de sus decisiones utiliza las conclusiones del sistema de reportes como fundamento jurídico de los fallos de reclamaciones colectivas, mediante las referencias cruzadas $^{50}$. La jurisprudencia del cEDs, en el marco de las reclamaciones colectivas, ha tenido influencia en aquella del sistema de reportes, a la vez que la ha tomado como su punto de partida y re-

48 En la decisión de fondo de la reclamación colectiva 18 de 2003 -Organización Mundial Contra la Tortura vs. Irlanda-, el CEDs ha tomado en consideración, para la aplicación del artículo 17 de la Carta, la Convención de las Naciones Unidas sobre los Derechos de los Niños y la jurisprudencia del órgano competente para pronunciarse sobre su observancia, a saber, el Comité de Derechos del Niño.

JIMENA QUESADA, Luis. Les systemes conventionnels de réclamations collectives: la pratique du Comité Européen des Droits Sociaux.

50 Las decisiones de fondo de las reclamaciones 17, 19, 20 y 21 de 2003 de la Organización Mundial Contra la Tortura vs. Grecia, Italia, Portugal y Bélgica, respectivamente, se basan en la interpretación jurídica que el Comité realizó del artículo 17 de la Carta en las Conclusiones del Informe de 2001 ferencia, poniéndose en evidencia una fuerte interacción entre el contenido de ambos mecanismos, lo cual refuerza la integralidad y coherencia en los pronunciamientos de este órgano ${ }^{51}$.

Por otra parte, el contenido de las decisiones de fondo tiene un valor jurídico porque acoge las reglas de interpretación que se derivan del carácter de tratado de derechos humanos de la CSE, las cuales complementan las técnicas generales de interpretación ${ }^{52}$. Lo anterior tiene implicaciones desde la perspectiva de la aplicación y la efectividad de IOS DEsc. En efecto, desde sus primeros pronunciamientos, específicamente en la decisión de fondo sobre la Reclamación Colectiva 1 de 1999 (Comisión Internacional de Juristas contra Portugal), el Comité ha reconocido que la Carta Social es un "instrumento de protección de los Derechos Humanos" ${ }^{53}$.

Este es, entonces, el punto de partida para que a lo largo de su jurisprudencia el CEDs haya utilizado como criterios interpretativos: i. la aplicación más favorable de los derechos, contemplada en el artículo 32 de la Carta ${ }^{54 ;}$ ii. La progresividad o la no regresión de los derechos que no solamente está establecida de manera explícita en algunas disposiciones de la Carta $^{55}$, sino tam-

51 JIMENA QUESADA, Luis. Les systemes conventionnels de réclamations collectives: la pratique du Comité Européen des Droits Sociaux.

$52 \quad$ Ibid

53 Párr. 32

54 Casos que comprenden la aplicación del artículo 19 de la Carta, relacionado con los derechos de los trabajadores migrantes, al igual que otros casos que involucran los derechos de refugiados y apátridas.

55 Respecto de la reducción de la semana de trabajo, previsto en el artículo 2 o frente a la institución de servicios de salud en el trabajo, previsto en el artículo 3 . 
bién es el fundamento de algunas decisiones de fondo ${ }^{56}$; iii. La técnica de las obligaciones positivas, sin perjuicio del margen de apreciación de los Estados 57 ; y, iv. La igualdad y la no-discriminación, principios establecidos de manera explícita en la Carta $^{58}$, los cuales orientan las decisiones de fondo y contribuyen a la garantía efectiva de diversos derechos contenidos en la CSE, siendo principios que no constituyen un derecho autónomo sino un criterio de aplicación para todos los demás derechos ${ }^{59}$.

Sin embargo, existe un aspecto problemático. A diferencia de otros mecanismos internacionales de protección de derechos humanos, ni el Protocolo Adicional ni el reglamento del cEDs exigen el agotamiento de recursos internos para la procedencia de la reclamación, lo cual ha sido reiterado por el CEDS al pronunciarse respecto de la admisibilidad de algunas reclamaciones ${ }^{60}$. Igualmente, existen otras reglas procedimentales en que los principios de res judicata y non bis idem, tal y como aplican en relación con otros mecanismos internacionales de protección de los derechos humanos, no tengan aplicación en el sistema de reclamaciones colectivas ${ }^{61}$.

56 Comité Europeo de Derechos Sociales. Reclamación 58/2009, COHRE contra Italia. Decisión de fondo del 25 de junio de 2010. Párr. 27.

57 Comité Europeo de Derechos Sociales. Reclamación 45/2007, INTERIGHTS contra Croacia. Decisión de fondo del 30 de marzo de 2009. Párrs. 61-64.

58 Carta Social Europea. Preámbulo y artículo E.

59 Comité Europeo de Derechos Sociales. Reclamación 13/2002, Autismo-Europa contra Francia. Decisión de fondo del 4 de noviembre de 2003.

60 Decisión de admisibilidad de la reclamación $n^{\circ} .31$ de 2005, CEDR contra Bulgaria.

61 JIMENA QUESADA, Luis. Les systemes conventionnels de réclamations collectives: la pratique du Comité Européen des Droits Sociaux.
Lo descrito puede evidenciarse en algunos pronunciamientos del cEDs. Es el caso de la decisión de la reclamación del Sindicato Nacional de las Profesiones del Turismo vs. Francia, donde el CEDs señaló que "la competencia de la jurisdicción nacional de sancionar los abusos no priva al CEDs de la competencia que le da el Protocolo que contempla las reclamaciones colectivas"62. Por otra parte, en la decisión de admisibilidad de la Comisión Internacional de Juristas vs. Portugal, el ceDs señaló que "Ni el hecho de que el Comité ya haya examinado la situación en el marco del sistema de reportes, ni el hecho de que la examine nuevamente durante ciclos de supervisión posteriores implica de por sí la inadmisibilidad de una reclamación colectiva relacionada con la misma disposición de la Carta y el mismo Estado parte" ${ }^{\prime 63}$. Esto puede ser cuestionado, pues si bien garantiza el principio de aplicación más favorable de los derechos y puede resultar en una mayor garantía para la observancia de los DESc por los Estados, desconoce el carácter subsidiario del SEDH y, con esto, la soberanía y el margen de apreciación de los Estados $^{64}$.

Ahora, respecto a la implementación de este mecanismo, cabe anotar que los Estados parte en la cSE están obligados a someterse al sistema de reportes, mientras que no lo están a prestar su consentimiento para aceptar la competencia del cEDs para examinar las reclamaciones colec-

\footnotetext{
62 Decisión de fondo del 10 de octubre de 2000 sobre la reclamación 6 de 1999 (Sindicato Nacional de las Profesiones del Turismo contra Francia), párr. 45.

63 Comité Europeo de Derechos Sociales.

64 Corte Europea de Derechos Humanos. Caso Lautsi.
} 
tivas $^{65}$. Esto muestra un contraste en las exigencias y los mecanismos de protección de los DESC y los derechos civiles y políticos: respecto de los derechos contenidos en el CEDH, fue suprimida la posibilidad de aceptación de la competencia de la Corte EDH y se exigió a los Estados parte la aceptación obligatoria. Adicionalmente, una de las dificultades que afronta el mecanismo de reclamaciones colectivas es que hasta 2011 solamente catorce Estados habían ratificado su adhesión al Protocolo.

Respecto a los mecanismos de ejecución de decisiones del CEDS, existen dos problemas centrales. De una parte, la manera en la que se ha regulado la publicidad de las decisiones del CEDS puede tener un efecto negativo sobre su efectividad, pues son publicadas después de un periodo de cuatro meses, a diferencia de los demás documentos y pronunciamientos en las reclamaciones colectivas, que son publicados de manera inmediata ${ }^{66}$. El tiempo excesivo de la publicación de la decisión resulta en una dilatación de su cumplimiento por parte del Estado. De otra parte, existen críticas respecto a la supervisión del cumplimiento, pues el Comité de Ministros del Consejo de Europa no ha diseñado un mecanismo mediante el cual se vigile la ejecución de las recomendaciones que se hacen a los Estados ${ }^{67}$.

65 Esto contrasta con el hecho de que la aceptación voluntaria de la competencia de la Corte EDH frente a las violaciones del CEDH fue suprimida y se exigió a los Estados parte su aceptación obligatoria. JIMENA QUESADA, Luis. Les systemes conventionnels de réclamations collectives: la pratique du Comité Européen des Droits Sociaux.
A pesar de que el CEDs no es una Corte y sus decisiones no tienen el mismo valor jurídico de una sentencia, sus decisiones tienen el carácter de soft law y son un criterio interpretativo de la CSE y un parámetro que puede orientar la conducta de los Estados. El hecho de que se siga un proceso con características contenciosas y que se utilicen los principios de interpretación propios de la hermenéutica jurídica y de los tratados de derechos humanos, resulta en que las decisiones del CEDs tengan un sólido respaldo jurídico. Se puede constatar que aunque los pronunciamientos no tengan una vocación reparatoria (no se condena al Estado) sí tienen una vocación preventiva. Asimismo, independientemente de las modalidades de ejecución de las decisiones del CEDS, una manera en la que han adquirido efectividad los derechos de la cSE es el hecho de que la interpretación legal (jurisprudencia) del CEDs ha sido acogida por los tribunales internacionales ${ }^{68}$ y ha tenido influencia sobre las jurisdicciones nacionales que aplican la ley de conformidad con las interpretaciones de la Carta ${ }^{69}$.

\section{Sistema Interamericano de Derechos Humanos: artículo 26 CADH y artículo 19 PSS}

En el SIDH existe un mecanismo de informes que permite llevar a cabo supervisión de la observancia de los DESC $y$, a diferencia del SEDH, existe

68 Recepción de la Corte Europea de las decisiones del cEDs: Sorensen y Rasmussen contra Dinamarca, 11 de enero de 2006, párrs. 34-46 (utiliza decisión de fondo del 22 de mayo de 2003, reclamación 12/2002, Confederación de empresas suecas contra Suecia); Demir y Baykara contra Turquía, 12 de noviembre de 2008 (párrs. 49 y 50, utiliza la jurisprudencia del CEDs relativa al artículo 6.2 Carta Social).

69 JIMENA QUESADA, Luis. Les systemes conventionnels de réclamations collectives: la pratique du Comité Européen des Droits Sociaux. 
también un sistema directo de carácter jurisdiccional que, aunque no ha sido utilizado en todo su alcance, permite exigibilidad directa de estos derechos.

Respecto al sistema de informes en el SIDH, encontramos que la CIDH, uno de sus órganos principales, cuya misión es la promoción y protección de los derechos humanos en las Américas ${ }^{70}$, tiene entre sus funciones preparar estudios e informes $^{71}$. La CIDH ha realizado, con base en visitas in $10 \mathrm{Co}^{72}, 94$ informes de países e informes temáticos sobre derechos humanos ${ }^{73}$. En estos, la CIDH ha hecho referencia a la situación de DESc en las naciones, aunque estos análisis se han centrado sobre todo en el acceso a las condiciones que permitan la plena garantía de los DESc para sectores vulnerables. En el 2011, por ejemplo, la CIDH presentó un informe relacionado con la garantía de DEsc para las mujeres: “El Trabajo, la Educación y los Recursos de las Mujeres: La Ruta Hacia la Igualdad en la Garantía de los Derechos Económicos, Sociales y Culturales".

Los informes tienen una función importante no solo para la supervisión de la actividad del Estado en cumplimiento de los DESC y de su si-

70 CANCADO TRINDADE, Antonio Augusto. El sistema interamericano de protección de los derechos humanos (1948-2000). En: GÓMEZ ISA, Felipe; PUREZA, José Manuel. La protección internacional de los derechos humanos en los albores del siglo XXI. Humanitarian Net. Universidad de Bilbao. Bilbao, 2004.

71 Convención Americana sobre Derechos Humanos. Artículo 41.c.

72 El artículo 39 del Reglamento de la CIDH dispone: "Si lo considera necesario y conveniente, la Comisión podrá realizar una investigación in loco, para cuyo eficaz cumplimiento solicitará las facilidades pertinentes, que serán proporcionadas por el Estado en cuestión".

73 Comisión Interamericana de Derechos Humanos. Informe anual de la Comisión Interamericana de Derechos Humanos 2011. tuación general en la región, sino también para que los Estados y la sociedad evalúen la implementación doméstica de sus compromisos. Sin embargo, el hecho de que la situación de los DESC haya sido analizada primordialmente a la luz de la protección de grupos vulnerables y no teniendo en cuenta la satisfacción de estos derechos para la totalidad de la población, supone un punto débil en el SIDH frente a la evaluación estructural de la implementación de DESC.

No obstante, a través del PSs se introdujo una norma que refuerza el mecanismo de informes relativos a DESC en el SIDH. El artículo 19 del PSS dispone el compromiso de los Estados parte de presentar informes periódicos respecto de las medidas progresivas que hayan adoptado para asegurar el debido respeto de los derechos consagrados en dicho instrumento. Estos informes son presentados ante el Consejo Interamericano Económico y Social y el Consejo Interamericano para la Educación, la Ciencia y la Cultura, quienes los examinan e incluyen en el informe anual que presentan ante la OEA. Igualmente, el informe es remitido a la CIDH, quien podrá formular las observaciones y recomendaciones que considere pertinentes ${ }^{74}$.

En sus "Observaciones Generales sobre el sistema de informes del artículo 19 del Protocolo de San Salvador", la CIDH ha reconocido que "Ios Estados pueden cumplir con sus obligaciones escogiendo entre un amplio espectro de cursos de acción y de políticas (...)", pero ha precisado que el artículo 26 exige "comparar la extensión de la titularidad y del contenido de los derechos

74 PSs. Artículo 19.7. 
y de las garantías concedidas (en un Estado) a través de nuevas medidas normativas con la situación de reconocimiento, extensión y alcance previos" ${ }^{75}$. Así, la cIDH establece en este informe parámetros de evaluación y de presentación de informes estatales que comprenden la elaboración de indicadores de progreso (estructurales, de proceso y de resultado).

Los indicadores estructurales determinan qué medidas dispone el Estado para implementar los derechos del pss; los indicadores de proceso evalúan la calidad y magnitud de las anteriores medidas, a través de la medición de su alcance, cobertura y el contenido que fijan; y, finalmente, los indicadores de resultado buscan calcular el impacto real de todas las estrategias o programas. Estos indicadores deben analizarse de conformidad con i) las capacidades estatales, que comprenden las reglas del aparato estatal, las relaciones interinstitucionales y los recursos humanos y ii) el contexto financiero, que comprende la disponibilidad efectiva de los recursos del Estado para ejecutar el gasto público y la manera en la que este es distribuido.

Teniendo en cuenta que los reportes requeridos por el artículo 19 pss exigen a los Estados dar cuenta de las medidas emprendidas respecto de los derechos consagrados en el pss de acuerdo con criterios que desarrolla la $\mathrm{CIDH}$ en su informe, se trata de un mecanismo que permite el monitoreo de su observancia y a los Estados examinar su propia actividad en aras de la implementación de los DESc. No obstante, dado

75 Informe que los informes presentados no necesariamente dan lugar a una observación o recomendación de la cIDH, la información recopilada y analizada por los Estados no siempre desemboca en un pronunciamiento de este órgano, que aun cuando no es jurídicamente vinculante, en su carácter de soft law puede generar otros efectos como la fijación de parámetros o la creación de expectativas de conducta ${ }^{76}$.

Ahora, en cuanto a los mecanismos de justiciabilidad directa, encontramos que el artículo 26 de la CADH da lugar a exigibilidad directa de los derechos económicos, sociales y culturales derivados de la Carta de la oEA. Esto es viable mediante los mecanismos de protección consagrados en la CADH, respecto de cuya puesta en marcha no existe una diferenciación entre los derechos contenidos en el Capítulo II CADH (civiles y políticos) y aquellos contenidos en el Capítulo III (económicos, sociales y culturales) ${ }^{77}$.

Los mecanismos de protección en la CADH comprenden un sistema de peticiones individuales, reglamentado por los artículos 44 a 51 y 61 a 69 de la CADH. Este mecanismo puede ser utilizado para alegar el incumplimiento de un Estado parte dela observancia de los derechos contenidos en la CADH y hacer exigible su cumplimiento. Los procesos contenciosos ante el SIDH se estructuran en dos etapas: las peticiones son examinadas por la CIDH mediante un procedimiento que puede dar lugar a una solución amistosa o a un informe de la cIDH con las conclusiones respecto

TORO HUERTA, Mauricio Iván del. El fenómeno del soft law y las nuevas perspectivas del derecho internacional. Curso DIP. 2007. UMAG.

77 Courtis 
a la violación de los derechos y sus recomendaciones al Estado ${ }^{78}$. Una vez se surte esta etapa, y en caso de que la CIDH encuentre que hay mérito para ello, el caso es sometido a la decisión de la Corte IDH, órgano encargado de la interpretación y aplicación de la $\mathrm{CADH}^{79}$. Esta Corte determinará si efectivamente hubo una violación por parte del Estado, podrá declarar su responsabilidad internacional y, en este caso, exigir la reparación correspondiente.

Es importante tener en cuenta que la legitimación activa ante el SIDH la tienen las víctimas o sus representantes. Víctima ha sido entendido en el SIDH como la persona o grupo de ellas que haya sufrido la violación a derechos contenidos en la CADH. Estas deben ser identificadas e individualizadas ${ }^{80}$. Excepcionalmente, la Corte IDH ha reconocido la posibilidad de que las víctimas no cumplan estos criterios, pero ha exigido que sean determinables ${ }^{81}$. Así, el procedimiento ante la Corte IDH tiene la vocación de protección de individuos, más que la de declarar la responsabilidad del Estado frente a políticas nacionales u otro tipo de medidas de carácter generalizado.

En los informes en el marco del sistema de peticiones, la CIDH se ha pronunciado en varias oportunidades sobre la violación al artículo 26. Las conclusiones de la $\mathrm{CIDH}$ frente a los alegatos so-

$78 \mathrm{CADH}$, Artículo 50

79 CADH. Artículos 62 y 63.

$80 \mathrm{CADH}$. Artículo 46.

81 Corte Interamericana de Derechos Humanos. Masacre de Mapiripán; Awas Tingni; Yakye Axa. bre violación al desarrollo progresivo de los DESC han estado basadas en el criterio según el cual estos derechos y las obligaciones correlativas que imponen a los Estados deben ser interpretados a la luz de los artículos 1 y 2 de la caDH y el Pss. En el informe Milton García Fajardo y otros v. Nicaragua ${ }^{82}$, aun cuando al momento de los hechos el Estado no había ratificado el PSS, la CIDH concluyó que el artículo 26 había sido violado, pues "en vez de adoptar medidas de desarrollo progresivo en beneficio de los trabajadores aduaneros, buscó reducir sus derechos, ocasionándoles perjuicios graves en sus derechos económicos y sociales", lo anterior con base en la interpretación del artículo $26 \mathrm{CADH}$ a la luz de los artículos 1 y 2 de la CADH y el pSs.

En el caso de la Asociación Nacional de Ex-Servidores del Instituto Peruano de Seguridad Social y otros v. Perú, la CIDH precisa el contenido del artículo 26 CADH al determinar que el derecho a la seguridad social se encuentra dentro de su campo y, consecuentemente, los Estados parte se encuentran en la obligación de procurar su desarrollo progresivo ${ }^{83}$. Adicionalmente, la $\mathrm{CIDH}$ recurre, tanto al pss como al Pacto Internacional de Derechos Económicos, Sociales y Culturales y a las observaciones del Comité de Derechos Económicos, Sociales y Culturales (propios del sistema universal de la onu), para puntualizar el contenido de la obligación de progresividad,

82 Comisión Interamericana de Derechos Humanos. Informe $\mathrm{n}^{\circ}$. 100/2001. Caso 11.381. Milton García Fajardo y otros v. Nicaragua. 11 de octubre de 2001.

83 Comisión Interamericana de Derechos Humanos. Informe n. 38/09. Caso12.670. Admisibilidad y fondo. Asociación Nacional de Ex-Servidores del Instituto Peruano de Seguridad Social y otros v. Perú. 27 de marzo de 2009. Párr. 133. 
estableciendo que supone la prohibición de no regresividad $^{84}$.

Posteriormente, en el informe Joffré Fernández Valdivieso y otros v. Perú ${ }^{85}$, en el cual la $\mathrm{CIDH}$ se pronunció frente a si la creación de topes máximos a las pensiones suponía la violación del artículo 26 de la $\mathrm{CADH}$, la $\mathrm{CIDH}$ reiteró que el desarrollo progresivo de los DESC a los que hace referencia esta norma debe ser analizado de acuerdo con la realidad económica del país y los costos de vida en su contexto ${ }^{86}$. De este modo, teniendo en cuenta que la medida implementada por Nicaragua había obedecido a ajustes económicos y que estaba encaminada a lograr una mayor cobertura para la población, la $\mathrm{CIDH}$ consideró que no había lugar a una violación del artículo 26.

Los anteriores casos, emblemáticos dentro de la actividad de la CIDH relativa a los DESC en el sistema de peticiones individuales, ponen de manifiesto que este órgano ha realizado un esfuerzo interpretativo para dotar de contenido, tanto a los derechos individuales como a las obligaciones estatales comprendidas en el artículo 26 CADH. En este esfuerzo, la $\mathrm{CIDH}$ se ha aventurado a utilizar otros instrumentos internacionales relativos a la protección de DEsc. Vemos entonces cómo la CIDH ha hecho uso de las facultades que la CADH le confiere para pronunciarse sobre las violaciones a los derechos en ella contenidos. Sin embargo, es necesario constatar que sus

\footnotetext{
84 Ibid. 27 de marzo de 2009. Párr. 147.

85 Informe $n^{\circ}$. 167/11. Petición 12.077. Inadmisibilidad. Joffré Fernández Valdivieso y otros v. Perú. 2 de noviembre de 2011.

informes sobre DESC no son numerosos y los casos que ha sometido ante la Corte IDH relativos a la violación del artículo 26 han sido aún menos significativos en cantidad, lo que demuestra un estancamiento de la CIDH y una baja aplicación de esta disposición en el sistema.

En relación con la actividad de la Corte IDH, encontramos que a pesar de que la CADH le otorga competencia jurisdiccional para pronunciarse respecto de la violación del artículo 26 , hasta la fecha esta disposición ha sido desconocida en su labor jurisdiccional. No solamente la Corte nunca ha declarado la responsabilidad internacional del Estado frente a esta disposición, sino que se ha abstenido de analizarla, evitando desarrollar una línea jurisprudencial clara con respecto a su naturaleza y alcance. En lugar de utilizar la vía directa del artículo 26 para la justiciabilidad de los DESc, la Corte ha optado por proteger estos derechos a través de la vía indirecta de la interpretación extensiva de los derechos civiles y políticos contenidos en el Capítulo II CADH. Los pocos casos en los que se ha alegado la violación del artículo 26 ponen en evidencia la timidez de la Corte para analizar y dar aplicación a su contenido, de conformidad con el mandato legal que le confieren los artículos 62 y 63 de la $\mathrm{CADH}$.

En el caso Instituto de Reeducación del Menor v. Paraguay, los representantes de las víctimas alegaron la violación al artículo 26 de la $\mathrm{CADH}$ en virtud del desconocimiento del Estado de los derechos a la salud y a la educación de los menores recluidos en el Instituto, quienes eran vulnerables. La Corte IDH se abstiene de pronunciarse sobre la violación de este artículo pues 
considera que el análisis de los hechos se aborda suficientemente desde los derechos a la vida (artículo 4), a la integridad personal (artículo 5) y los derechos de los niños (artículo 19) ${ }^{87}$.

En el caso Cinco Pensionistas v. Perú, si bien la Corte IDH reconoció su competencia para pronunciarse respecto a los derechos que se desprenden del artículo 26 de la CADH, desestimó la solicitud señalando que una violación al desarrollo progresivo se debe medir de acuerdo con la "creciente cobertura de los derechos económicos, sociales y culturales en general, y a la seguridad social y a la pensión en particular, sobre el conjunto de la población (...) y no en función de las circunstancias de un muy limitado grupo (...) no necesariamente representativos de la situación general prevaleciente" 88 .

En el caso Yakye Axa v. Paraguay, aun cuando el Estado se allanó parcialmente a la pretensión de los representantes de las víctimas respecto de violación al desarrollo progresivo de los derechos económicos, sociales y culturales establecida en el artículo 26 de la $\mathrm{CADH}$, la Corte IDH no analiza ni toma una postura sobre la violación a este derecho, y enmarca los hechos del caso de esta comunidad indígena cuyo territorio ancestral había sido vulnerado, en la violación a los derechos a la vida y a la propiedad, contenidos respectivamente en los artículos 4 y 21 de la $\mathrm{CADH}$.

87 Corte IDH. Caso Instituto de Reeducación del Menor vs. Paraguay. Excepciones Preliminares, Fondo, Reparaciones y Costas. Sentencia de 2 de septiembre de 2004. Párr. 255.

88 Corte IDH. Caso Cinco Pensionistas vs. Perú. Fondo, Reparaciones y Costas. Sentencia de 28 de febrero de 2003. Serie $C n^{\circ}$. 98. Párr. 147.
En el caso Acevedo Jaramillo v. Perú, el representante de las víctimas alega la violación al artículo 26 CADH en virtud de los despidos masivos y arbitrarios de los empleados de Lima afiliados al SITRAMUN, desconociéndose el derecho al trabajo y a la seguridad social. En este caso, la Corte $\mathrm{CIDH}$ se abstiene de pronunciarse respecto de la violación al artículo 26, en tanto el desconocimiento de los derechos laborales es enmarcado en la violación al artículo 25 sobre garantías judiciales, dado que el Estado peruano no cumplió las sentencias de la jurisdicción nacional que ampararon estos derechos ${ }^{89}$.

En el caso Acevedo Buendía v. Perú ${ }^{90}$, la Corte IDH reconoce nuevamente su competencia respecto del artículo 26 y da un paso hacia la protección de los DESC, al señalar que las obligaciones de respeto y garantía contenidas en los artículos 1.1 y 2 CADH son aplicables también respecto de los derechos contenidos en el artículo 26. Sin embargo, en el análisis de los hechos, la Corte IDH encontró que las medidas demandadas no solamente eran contrarias al desarrollo progresivo del derecho a una pensión, sino que las violaciones alegadas se enmarcaban en los derechos a la propiedad y a las garantías judiciales (artículos 21 y $25 \mathrm{CADH}$, respectivamente).

Recientemente, en el caso Sarayaku v. Ecuador, aún cuando los representantes de esta comunidad indígena alegaron la violación del artículo

89 Corte IDH. Caso Acevedo Jaramillo y Otros vs. Perú. Excepciones Preliminares, Fondo, Reparaciones y Costas. Sentencia de 7 de febrero de 2006. Párr. 278.

90 Corte IDH. Caso Acevedo Buendía y otros ("Cesantes y jubilados de la Contraloría") vs. Perú. Excepción Preliminar, Fondo, Reparaciones y Costas. Sentencia de 1 de julio de 2009. Serie C nº 198 
26 CADH en razón del desconocimiento del derecho a la cultura, la Corte IDH nuevamente es reticente a declarar la violación de esta disposición. Los representantes de las víctimas alegaron que la concesión otorgada por Ecuador sobre el territorio del pueblo Sarayaku para la extracción petrolera ocasionaba la afectación de la relación del pueblo con su territorio, al desconocer su carácter sagrado y trastornar los usos y ritos tradicionales que formaban la identidad cultural de la comunidad. Sin embargo, la Corte IDH encontró que no correspondía analizar la violación del artículo 26, pues consideró que la violación a la identidad cultural había sido suficientemente analizada bajo el derecho a la propiedad (artículo 21 de la $\mathrm{CADH}^{91}$ ).

Ahora bien, el sistema de peticiones individuales puede ser utilizado también respecto del PSS. Dicho instrumento otorga competencia a los órganos del SIDH en los casos relacionados con las presuntas violaciones a los artículos 8.1.a y $13^{92}$, los cuales protegen respectivamente los derechos de sindicalización y educación. La protección sustancial de los DESC reconocidos en el PSs, en su mayoría, no encuentra entonces respaldo en los mecanismos de protección contenciosos existentes en el SIDH.

La Corte IDH ha sido igualmente tímida a la hora de poner en marcha la justiciabilidad directa de IOS DESC respecto de estas disposiciones del PSS. En el caso Instituto de Reeducación del Menor v. Paraguay, la Corte IDH se limitó a utilizar el ar-

\footnotetext{
91 Corte IDH. Caso Pueblo Indígena Kichwa de Sarayaku vs. Ecuador. Fondo y Reparaciones. Sentencia de 27 de junio de 2012. Párr. 230.

92 Protocolo de San Salvador. Artículo 19.6.
}

tículo 13 pss como un criterio para declarar la responsabilidad internacional del Estado por la violación a la vida y la integridad personal de los menores recluidos en el Instituto, sin declarar la violación autónoma de esta disposición, aun cuando Paraguay había ratificado el pss.

Sin perjuicio de lo anterior, es importante resaltar que la función principal que cumple el pSs en la justiciabilidad de los DESc, en el seno del SIDH, es el hecho de que ofrece unos criterios de interpretación para determinar el contenido y alcance, tanto del artículo 26 de la CADH como de los demás derechos contenidos en este instrumento, puesto que estos tienen dimensiones económicas, sociales y culturales. En el caso Yakye Axa v. Paraguay, la Corte IDH utiliza los artículos 10 (Derecho a la Salud); 11 (Derecho a un Medio Ambiente Sano); 12 (Derecho a la Alimentación); 13 (Derecho a la Educación) y 14 (Derecho a los Beneficios de la Cultura) del pss como criterios determinantes para declarar la violación a la vida digna (artículo $4.1 \mathrm{CADH})^{93}$.

De manera similar, en el caso Baena Ricardo v. Panamá, aunque la Corte IDH reconoce su competencia para pronunciarse sobre las violaciones del artículo 8.1.a del pss, los hechos se presentaron con anterioridad a la ratificación del instrumento por Panamá, razón por la cual la Corte IDH se abstiene de pronunciarse frente a la violación de esta disposición. No obstante, la libertad de asociación en materia laboral contemplada en el artículo 16 CADH es interpretada de conformidad con otra disposición del pSs: ar-

93 Corte IDH. Caso Comunidad indigena Yakye Axa vs. Paraguay. Fondo, Reparaciones y Costas. Sentencia de 17 de junio de 2005. Párr. 163. 
tículo 8.3 que reconoce la libertad de toda persona de no ser obligada a asociarse ${ }^{94}$.

Por otra parte, en el caso Niñas Yean y Bosico v. República Dominicana, la Corte IDH tomó en consideración el pss para la interpretación del deber de protección especial a los niños, consagrado en el artículo $19 \mathrm{CADH}$, concluyendo que los Estados están en la obligación de “proveer educación primaria gratuita a todos los menores, en un ambiente y condiciones propicias para su pleno desarrollo intelectual" 95 .

\section{Relación comparativa de los mecanis- mos directos de protección de DESC en el SEDH Y el SIDH}

A partir de lo expuesto, encontramos que respecto de los mecanismos de protección directa de IOS DESC existen diferencias sustanciales entre el SIDH y el SEDH. La primera diferencia es que en el SIDH lOS DESC pueden ser exigibles a través de los mismos mecanismos de protección de los derechos civiles y políticos: el sistema de peticiones individuales, otorgando así competencia tanto a la $\mathrm{CIDH}$ como a la Corte IDH para pronunciarse respecto de la eventual violación y poniendo en marcha un mecanismo de carácter eminentemente judicial para su garantía. En contraste, en el SEDH los mecanismos para la garantía de IOS DESC no son los mismos de los derechos civiles y políticos y no existe un mecanismo judicial, únicamente un mecanismo no contencioso

94 Corte IDH. Caso Baena Ricardo vs. Panamá. Fondo, Reparaciones y Costas. Sentencia de 2 de febrero de 2001. Párr. 159.

95 Corte IDH. Caso Niñas Yean y Bosico v. República Dominicana. Fondo, Reparaciones y Costas. Sentencia de 8 de septiembre de 2005. Párr. 185. (reportes) y otro cuasi-contencioso (reclamaciones colectivas). Lo anterior demuestra entonces cómo el SIDH ha sido más progresista a la hora de establecer mecanismos de garantía para los DESC, pues no solamente en términos de garantías no existe una diferenciación de estos derechos y los de carácter civil y político, sino que se ha dispuesto el mecanismo de mayor fuerza jurídica para su protección.

Encontramos que la puesta en marcha de los mecanismos directos en uno y otro sistema hace que la balanza se incline a favor del SEDH si se evalúa su efectividad. Por un lado, los órganos del SIDH, tanto la CIDH como la Corte IDH, no han hecho pleno uso de las facultades que la CADH les confiere para interpretar y aplicar los artícuIos 26 CADH y 8.1.a y 13 pSs. Además, el sistema de informes en el SIDH tampoco ha sido utilizado en todo su potencial, pues los informes de los países no necesariamente desembocan en observaciones o recomendaciones de la CIDH y en cuanto a los informes temáticos se ha restringido el análisis de los DESc a los sectores vulnerables de la población, desconociendo su carácter general. Así, las vías directas de protección en el SIDH han sido subutilizadas.

En cambio, los mecanismos de informes y reclamaciones colectivas desarrollados en el SEDH suponen un análisis completo y riguroso, tanto de la actividad del Estado como de las disposiciones normativas de la CSE por parte de un órgano especializado: el CEDS. Si bien se trata de pronunciamientos soft law cuya implementación se ve afectada por el hecho de que órganos de conformación política están involucrados, los pronunciamientos del CEDS constituyen un refe- 
rente conceptual y construyen parámetros de conducta para los Estados que no se han desarrollado en el SIDH.

Finalmente, cabe destacar un aspecto de los mecanismos directos de protección en el SEDH y en el SIDH que debe ser complementado uno con otro. Mientras que en el SEDH, el sistema cuasicontencioso de reclamaciones colectivas está encaminado a una protección colectiva, se dirige a medidas estructurales de política social de carácter general y está menos dado a proteger individuos, en el SIDH se refuerza la protección de individuos al exigir que las víctimas estén individualizadas e identificadas. En este sentido, el SEDH podría complementarse con una ampliación del sistema de reclamaciones colectivas que permita la protección del individuo y el SIDH podría admitir que se cuestionen las medidas o políticas de carácter general en materia de DESc, aun cuando sus víctimas no puedan ser plenamente identificadas, cuando estas medidas generales desconozcan la prohibición de regresividad en abstracto.

\section{B. Vía indirecta}

\section{Sistema Europeo de Derechos Humanos: jurisprudencia Corte EDH}

La protección cuasi-jurisdiccional de los derechos contenidos en la CSE, que compete al CEDS, es el mecanismo principal mediante el cual en el SEDH se ha garantizado la indivisibilidad e interdependencia de los derechos humanos. La competencia de la Corte EDH se restringe a los derechos contenidos en la Convención Europea
(CEDH), la cual se concentra principalmente en derechos civiles y políticos, aunque en el Primer Protocolo Adicional, en los artículos 1 y 2 se consagran, respectivamente, el derecho a la propiedad y a la educación.

Pese a ello, aunque la competencia de la Corte no se extiende a la protección de los DESc y existen los mecanismos de protección directa ya referidos, la jurisprudencia de la Corte EDH ha realizado en varias ocasiones una interpretación extensiva de los derechos contenidos en la CEDH, de modo que se ha alcanzado una protección indirecta de los DESC.

En 1979, la Corte EDH, caso Airey contra Irland $a^{96}$ afirma por primera vez "nulle cloison étanche ne sépare la sphére des droits économiques et sociaux du domaine de la Convention"97. La peticionaria alega la violación del artículo 6 de la CEDH, debido proceso, dada su imposibilidad de obtener una orden judicial de separación de su esposo por carencia de los recursos necesarios para obtener asistencia legal. En la decisión, la Corte EDH reconoce que algunos derechos civiles y políticos (en este caso, asistencia legal comprendida dentro del debido proceso) tienen implicaciones de orden económico o social y, en este sentido, son efectivos únicamente en la medida en que se desplieguen medios económicos o sociales para alcanzarlos. Es decir, la Corte resalta la estrecha relación entre los derechos conocidos como "de primera generación" y los

Corte EDH. Caso Airey v. Irlanda. Decisión de fondo. Octubre 9 de 1979.

97 No existe una barrera infranqueable que separe la esfera de los derechos económicos y sociales del ámbito de la Convención (traducción de la autora). 
de "segunda generación". Es importante indicar que en este pronunciamiento el criterio definitivo de interpretación para reconocer la violación al artículo 6 fue la efectividad de los derechos, la cual de conformidad con el artículo 1 de la CEDH debe ser garantizada por los Estados parte y les impone obligaciones positivas (en el caso concreto la obligación positiva respecto del artículo 6 comprende la ayuda económica para la asistencia legal).

La decisión en el caso Airey contra Irlanda es una decisión pionera, pero no tuvo la influencia esperada ${ }^{98}$. La Corte fue tímida al aproximarse a los derechos sociales, lo que resulta en una jurisprudencia garantista pero esporádica ${ }^{99}$. La gran mayoría de solicitudes relacionadas con los derechos sociales son declaradas inadmisibles precisamente porque se refieren a asuntos considerados ajenos al campo material de aplicación de la Convención. Sin embargo, este caso es el punto de partida para la interpretación extensiva de los derechos de la Convención.

La Corte EDH, a través de técnicas de interpretación como la conexión de derechos ${ }^{100}$, la prohibición de discriminación y la utilización de la CSE ha logrado que a través de peticiones individuales se constaten violaciones a la CEDH que tienen importantes consecuencias sobre protección de

98 BRILLAT, Régis. Les techniques normatives et juridictionnelles de protection International des droits sociaux.

99 Ibid.

100 La técnica de conexión de derechos, tal como la ha definido Luis Jimena Quesada, demuestra una práctica hermenéutica en la Corte EDH en la cual se protegen situaciones o derechos no contemplados en el $\mathrm{CEDH}$. Esto se ha hecho sobre todo a través del derecho a la integridad (artículo $3 \mathrm{CEDH}$ ) y el respeto a la vida familiar y al domicilio (artículo 8 CEDH). derechos sociales. Si bien en el caso Airey se tuteló la protección al artículo 6 (debido proceso), examinaremos cómo otras disposiciones han dado lugar a jurisprudencia garantista sobre derechos económicos, sociales y culturales.

\subsection{Protección de los DESC con base en la prohibición de tortura y de tratos crueles, inhumanos y degradantes}

El artículo $3 \mathrm{CEDH}$, que consagra la prohibición de tortura y tratos crueles, inhumanos o degradantes, ha sido interpretado de manera extensiva hasta incluir la prohibición de cualquier trato que alcance un mínimo de severidad y que involucre el sufrimiento personal, resultando en la humillación o sentimiento de inferioridad que rompe la resistencia de un individuo ${ }^{101}$. Así, la Corte ha establecido que esta prohibición exige, en ciertos casos, obligaciones positivas del Estado para ofrecer garantías económicas y sociales. Esto se ha presentado respecto de la exigencia de atención médica y provisión de hogar.

En el caso Z y Otros contra el Reino Unido ${ }^{102}$, la Corte declaró la violación del artículo 3 respecto de cuatro hermanos menores de edad por descuido y abuso por parte de sus padres, sin que el Estado, teniendo conocimiento de su situación, hubiera tomado medidas para detener tal situación. Este fallo pone de manifiesto que se presenta un maltrato a los menores, no solo por violencia física y psicológica al interior de su

101 Corte Europea de Derechos Humanos. Caso Pretty contra Reino Unido. Decisión de fondo. Abril 29 de 2002.

102 Corte Europea de Derechos Humanos. Caso $Z$ y otros contra Reino Unido. Decisión de fondo. Mayo 10 de 2001. 
familia, sino por las condiciones sanitarias en las que vivían y su insuficiente alimentación y vestuario. La Corte declaró al Reino Unido responsable por la violación del artículo 3, pues reconoce el deber del Estado de desplegar medidas de protección respecto de los niños (artículo 7 CSE), de modo que las condiciones en las que viven no ocasione una situación que pueda ser calificada de trato inhumano o degradante. Así, la Corte reconoce indirectamente el deber del Estado de velar por unas garantías mínimas (de alimentación, atención médica, condiciones sanitarias), que aunque no son reconocidas como derechos del CEDH y hacen parte del terreno de la CSE (protección de los niños, artículo 7; derecho a la salud, artículo 11; a la asistencia social y médica, artículo 13), hacen parte de las obligaciones positivas del Estado.

Igualmente, en el caso O 'Rourke contra el Reino Unido ${ }^{103}$ la Corte reconoció la posibilidad de una violación al artículo 3 ante una eventual negligencia del Estado frente a la obligación de proveer un techo, lo cual, en casos de extrema necesidad, desconocía la prohibición de maltrato contenida en el núcleo del derecho consagrado en el mencionado artículo.

En el caso D. contra el Reino Unido ${ }^{104}$, la Corte EDH sostiene que a pesar de la facultad de los Estados para controlar la entrada, residencia y expulsión de extranjeros de su territorio, la deportación del solicitante implicaría un trato inhumano y degradante, en contravención del

103 Corte EDH. Caso O'Rourke v. Reino Unido. Decisión de admisibilidad. Junio 26 de 2001.

Corte EDH. Caso D v. Reino Unido. Decisión de fondo. Abril 21 de 1997. artículo 3 cEDH. Lo anterior porque el solicitante, detenido a su ingreso al Reino Unido por porte ilegal de estupefacientes y que sería deportado a St. Kitts (país de origen), fue diagnosticado con VIH. La expulsión lo expondría al riesgo de morir, dadas las condiciones de atención médica en su país, por lo que el Reino Unido se encuentra en el deber de asumir su cuidado y tratamiento médico. Nuevamente, en aras de la protección del artículo 3 de la CEDH, se reconoce la obligación de los Estados de prestar asistencia médica adecuada y suficiente a los individuos bajo su jurisdicción, reconocimiento que supone la protección del artículo 11 y 13 de la CSE.

\subsection{Protección de los DESC con base en el principio de no discriminación}

El artículo 14 CEDH consagra la prohibición de discriminación y aplica con relación a todos los derechos contemplados en el $\mathrm{CEDH}^{105}$. El artículo 14 CEDH ha dado lugar a un segundo método interpretativo mediante el cual se puede alcanzar la protección de los DESC a través del CEDH y su aplicación mediante la competencia jurisdiccional de la Corte EDH. La aplicación de este principio con relación a otro derecho contenido en el CEDH ha logrado una "permeabilización del tratado europeo a los derechos sociales"106.

La aplicación combinada del artículo 14 ha permitido el reconocimiento del derecho a la seguridad social (artículo 12 cSE). Esto se evidencia

\footnotetext{
105 CANCADo TRINDADE, Antonio Augusto. The justiciability of civil Rights in the social field, the indirect justiciability of social Rights. P. 140.

106 JIMENA QUESADA, Luis. La jurisprudencia europea sobre derechos sociales. P. 286.
} 
en el caso Andrejeva contra Letonia ${ }^{107}$; la Corte EDH declaró que la falta de reconocimiento de la pensión de jubilación del solicitante violaba el derecho a la propiedad, contenido en el artículo 1 del Protocolo Adicional del CEDH con relación a su artículo 14. Dado que el no reconocimiento de la pensión obedecía al hecho de que los años de trabajo cotizados habían tenido lugar cuando Letonia aún hacía parte de la Unión Soviética, esta actuación del Estado suponía un trato diferenciado del solicitante respecto de otros nacionales. Igualmente, en Muñoz Díaz contra España ${ }^{108}$, la Corte EDH reconoció el derecho a la pensión a través de la aplicación del principio de no discriminación (artículo 14 CEDH) y el derecho a la propiedad (artículo 1, Protocolo Adicional 1), al declarar que el desconocimiento de la pensión de viudez a una mujer que contrajo matrimonio a través del rito gitano era contrario al CEDH.

El derecho al trabajo, contemplado en el artículo 1 CSE, también se ha visto protegido a través de la aplicación del principio de no discriminación contenido en el artículo 14 del CEDH. En el caso Thlimmenos contra Grecia ${ }^{109}$, la Corte EDH protege el acceso a una profesión al reconocer que el trato diferenciado, en razón de las creencias religiosas, de un aspirante a un trabajo como contador violaba la libertad de conciencia, pensamiento y religión, contenida en el artículo 9

107 Corte EDH. Caso Andrejeva v. Letonia. Decisión de fondo. Febrero 18 de 2009.

108 Corte EDH. Caso Muñoz Díaz v. España. Decisión de fondo. Diciembre 8 de 2009.

109 Corte EDH. Caso Thlimmenos Díaz v. Grecia. Decisión de fondo. Abril 6 de 2000. del CEDH, y la prohibición de discriminación del artículo 14.

Igualmente, la Corte EDH se ha aventurado a la protección del derecho a la vivienda, contemplado en el artículo 31 CSE, con fundamento en la prohibición de discriminación del artículo 14 CEDH. En el caso Karner contra Austria ${ }^{110}$, la Corte EDH declaró la responsabilidad del Estado al no proveer los beneficios de vivienda al compañero sobreviviente de una pareja homosexual. En este sentido, al reconocer una discriminación en razón de la orientación sexual, la cual es injustificada a la luz del CEDH, hubo lugar al reconocimiento y protección del derecho a la vivienda del solicitante.

\subsection{Correlación entre la CSE y el CEDH}

Además de la interpretación extensiva de los derechos del CEDH y de la aplicación del principio de no discriminación, se ha encontrado que existe otra técnica utilizada por la Corte EDH para la protección indirecta de los derechos sociales. Esta técnica comprende la "sinergia" o utilización conjunta de diversos instrumentos internacionales de derechos humanos para aplicación de los derechos contenidos en el CEDH. En el caso específico de los derechos sociales, se ha constatado la utilización de la cse y de la jurisprudencia del cEDS. El máximo exponente de esta técnica de protección corresponde al caso Demir y Baykara contra Turquía ${ }^{111}$, en donde se declara

110 Corte EDH. Caso Karner v. Austria. Decisión de fondo. Octubre 24 de 2003.

111 Corte EDH. Caso Demir y Baykara v. Turquía. Decisión de fondo. Noviembre 12 de 2008. 
la violación al artículo 11 CEDH relativo a la protección de derechos sindicales y de negociación colectiva, con fundamento en los artículos 5 y 6 de la CSE y en la jurisprudencia del Comité EDS, aun cuando Turquía no ha prestado su consentimiento para obligarse por dichas disposiciones. Se trata de una interpretación evolutiva que reconoce el derecho de huelga del artículo 11 como un elemento indisociable a él.

\section{Sistema Interamericano de Derechos Humanos: protección de los DESC a través de los derechos civiles y políticos}

La protección de la Corte IDH a derechos económicos, sociales o culturales ha estado marcada por dos tendencias ${ }^{112}$. Por un lado, esta protección ha sido posible por la interpretación extensiva de los derechos civiles y políticos contenidos en el Capítulo II de la CADH. Por otro lado, la Corte IDH ha abierto la vía a la protección de los DESC mediante el reconocimiento de la "especial vulnerabilidad" de grupos sociales particulares, lo que da lugar a una obligación acentuada por parte de los Estados.

\subsection{Vida digna}

La Corte IDH ha desarrollado, en virtud del artículo 4 CADH, el concepto de "vida digna" reconociendo los derechos de los individuos a salud, educación, alimentación y vivienda adecuada, en lugar de hacerlo a través del artículo $26 \mathrm{cADH}$. En el caso Niños de la Calle v. Guatemala, la

112 MELISH, Tara J. (2007). Rethinking the "LESS AS MORE" Thesis: Supranational Litigation of Economic, Social and Cultural Rights in the Americas.
Corte IDH establece la noción de "vida digna" y "acceso a las condiciones que garantizan una existencia digna", que cobra relevancia respecto de grupos especialmente vulnerables con fundamento en el artículo $4 \mathrm{CADH}^{113}$.

En el caso Panchito López, los derechos a salud y educación fueron reconocidos como componentes esenciales de la vida digna contemplada en el artículo 4, dadas las condiciones inadecuadas en las que se encontraban detenidos los menores en esta institución. Esta jurisprudencia se ha visto reiterada en casos como Bulacio v. Argentina y Myrna Mack v. Guatemala, en donde la Corte IDH ha dicho que el derecho a la vida, cuyo ejercicio es un requisito previo al ejercicio de otros derechos, exige que los Estados dispongan medidas positivas para asegurar las condiciones de vida digna.

Igualmente, en el caso Yakye Axa v. Paraguay, relacionado con una comunidad indígena desplazada de su territorio y desprovista de alimentación y condiciones de higiene. En este caso la violación por parte del Estado es declarada en dos dimensiones. Por un lado, respecto de la orden judicial nacional que prohibía a los miembros de la comunidad ingresar a su territorio ancestral para acceder por sí mismos a agua, alimentación y medicinas tradicionales. Por otro lado, la responsabilidad se desprende de la falta de adecuación e insuficiencia de medidas positivas para proveerles estas facilidades mientras la comunidad no podía acceder a su territorio. Adicionalmente, dada la particular relación de la comunidad con su tierra, se reconoció la afecta-

113 Corte IDH. Caso Niños de la Calle v. Guatemala. Párr. 144. 
ción de la identidad cultural. Estas afectaciones dieron lugar a que la Corte IDH declarara la violación al artículo 4 en razón de la afectación a la existencia digna.

En el caso Ximenes Lopes v. Brasil, la Corte IDH reconoció la obligación especial del Estado como garante del derecho a la salud de los sujetos al sistema nacional de atención médica. Estas obligaciones comprenden la regulación y monitoreo de estándares, condiciones y prácticas en el funcionamiento de la atención médica. La Corte reconoció esta obligación particular de los Estados respecto de personas con limitaciones intelectuales o físicas, cuando se encuentran bajo la custodia o cuidado del Estado.

En el caso Albán Cornejo v. Ecuador, la Corte IDH encontró violados los artículos 4 y 5 cADH por la muerte de un paciente en una práctica médica en un hospital privado. La Corte IDH estableció la responsabilidad de los Estados de regular y supervisar la prestación de servicios médicos, de modo que el derecho a la vida y la integridad personal sean garantizados.

\subsection{Derecho a la propiedad}

Otra aproximación jurisprudencial encaminada a la garantía de loS DESC se encuentra en pronunciamientos de la Corte IDH respecto al derecho a la propiedad, artículo 21 CADH. En casos relacionados con la posibilidad de comunidades indígenas de habitar, usar y disfrutar sus territorios ancestrales sin intromisión alguna, la Corte IDH ha dado un paso más allá reconociendo que el desconocimiento del derecho a la propiedad en estos casos comporta la afectación de la sub- sistencia económica, la identidad cultural y la autodeterminación. Esto se pone en evidencia en casos como AwasTingni v. Nicaragua, Saramaka v. Surinam y en el reciente caso Sarayaku v. Ecuador.

Igualmente, tomando como bandera la protección del derecho a la propiedad, la Corte IDH ha reconocido el derecho a pensión y, en un sentido más amplio, a la seguridad social. En el caso Cinco Pensionistas v. Perú, la Corte encontró que las reducciones del gobierno en los montos de pensiones infringían el derecho adquirido a pensión y, en consecuencia, desconocían el derecho a la propiedad. Igualmente, en este precedente la Corte IDH reafirmó la protección judicial que debe existir en el orden nacional para garantizar los derechos sociales reconocidos en la legislación doméstica.

\subsection{Libertad de Asociación}

La jurisprudencia de la Corte IDH ha contemplado a través del artículo 16 CADH, libertad de asociación, el derecho de los trabajadores de conformar sindicatos libremente. Si bien el artículo 16 hace referencia a una libertad más amplia, la que tiene toda persona de asociarse con fines ideológicos, religiosos, políticos, económicos, laborales, sociales o culturales, la Corte IDH destaca su dimensión laboral y apunta a la protección de los derechos de los trabajadores, contemplados en el artículo 8 del pss. Los casos más emblemáticos en esta materia son Baena Ricardo v. Panamá y Acevedo Jaramillo. 


\section{Relación comparativa de los mecanismos indirectos de protección de DESC en el SEDH y el SIDH}

Con relación a los mecanismos de protección indirecta es necesario señalar que, tanto la Corte EDH como la Corte IDH han realizado esfuerzos interpretativos de gran relevancia para fortalecer la relación de indivisibilidad e interdependencia de los derechos humanos. Esto se ha realizado a través de la extensión de los derechos civiles y políticos consagrados respectivamente en el CEDH y en la CADH, mediante el reconocimiento de su dimensión económica, social y cultural. Cabe rescatar que a través de estas interpretaciones se ha logrado una protección efectiva de los DESC en ambos sistemas y que esta tendencia interpretativa ha tenido una evolución exponencial.

No se puede perder de vista que la labor de la Corte EDH para tutelar los DESC a través de interpretación extensiva de ciertos artículos del CEDH, de la aplicación directa del principio de no discriminación contenido en este instrumento y de la interpretación de las normas del CEDH a partir de las normas de la CSE, obedece al hecho de que este órgano no tiene competencia directa para tutelarlos.

La Corte IDH, por el contrario, a pesar de contar con las facultades convencionales para tutelar de manera directa lOS DESC, se ha amparado exclusivamente bajo otros artículos de la CADH para su protección, con lo cual se ha paralizado la definición del contenido y los límites de estos derechos, al igual que los alcances de las obligaciones de los Estados específicamente en esta materia. Mientras que es meritoria la labor de la Corte EDH, esta misma labor de la Corte IDH es reprochable en el seno del SIDH. En ambos casos, las interpretaciones sistemáticas y extensivas de los derechos garantizan la protección efectiva de los DESC e integran el sistema, sin embargo, la Corte IDH se ha quedado corta en la labor de integración al reconocer la protección de los DESC exclusivamente como un asunto de relevancia desde los derechos civiles y políticos.

\section{CONCLUSIONES}

El análisis de las normas, instituciones y mecanismos de protección, directos e indirectos, para la garantía de los DESc evidencia que el SEDH y el SIDH pueden fortalecerse a través de la incorporación en cada uno de los avances alcanzados en el otro. Mientras que el SIDH ha sido más decidido a la hora de consagrar los DESC como normas jurídicas de carácter vinculante y ha sido más progresista en el reconocimiento normativo de los mecanismos de protección, el SEDH ha desarrollado y utilizado de manera provechosa mecanismos de carácter no contencioso y cuasi-contencioso para esbozar parámetros y recomendaciones más claras a los Estados.

A modo de recomendación, el SIDH debe seguir los pasos de su par europeo en la puesta en marcha de mecanismos de protección existentes, de modo que la aplicación de las normas de DESC por parte de los órganos competentes garantice la efectiva protección y supla los vacíos interpretativos actuales. El SEDH, por su parte, puede seguir al SIDH al reforzar los compromisos de los Estados, dotando de carácter vinculante todas las normas relativas a los DESC. 
En ambos sistemas son notables los esfuerzos interpretativos del máximo órgano jurisdiccional, la Corte EDH y la Corte IDH respectivamente, para el reconocimiento de la dimensión económica, social y cultural de los derechos civiles y políticos. La vía indirecta ha fortalecido la protección de los DESC y ha contribuido al reconocimiento del carácter de interdependencia e indivisibilidad de los derechos humanos. Además de que sería recomendable que en el SIDH la Corte IDH refuerce la protección de IOS DESC a través de su aplicación directa, la protección de IOS DESC podría hacerse más efectiva en ambos sistemas en la medida en que la jurisprudencia de cada uno tome como referencia y dé valor interpretativo a la jurisprudencia del otro. Se trata de la aplicación de la figura del corpus juris de los derechos humanos, mediante la cual tratados de derechos humanos de otros sistemas de protección y las decisiones de otros órganos internacionales pueden ser utilizados como un criterio de interpretación. Así, la experiencia jurisprudencial interamericana y la europea podría ampliarse y enriquecerse.

Finalmente, teniendo en cuenta que en ambos sistemas la "progresividad" y en particular el contexto institucional, económico y social de cada Estado, determinan el carácter de las obligaciones en materia de DESc, se hace necesario fortalecer tanto el sistema de reportes como la experticia técnica y jurídica de los órganos facultados para analizarlos y formular observaciones y recomendaciones a los Estados.

En este punto, el SIDH debe seguir el recorrido marcado por su par europeo. Si bien en el SEDH este desarrollo se ve frenado por los órganos políticos, el problema de la voluntad política de los Estados es un aspecto que se encuentra de manera transversal en la garantía de los DESC en ambos sistemas. La reticencia de los Estados a adquirir obligaciones que les impondrán cargas difíciles de cumplir es, finalmente, la fuerza invisible que se encuentra tras la timidez de los órganos del SIDH para pronunciarse directamente sobre esta materia o para los Estados parte del SEDH para reconocer normas jurídicas vinculantes en materia de DESc. En este punto, podría haber todavía un largo camino por delante, el cual va más allá de los desarrollos estrictamente jurídicos.

\section{Bibliografía}

\section{Doctrina}

ABRAMOVICH, Víctor; Rossı, Julieta. "La tutela de los derechos económicos, sociales y culturales". Revista de Estudios Socio-Jurídicos. Universidad del Rosario. Vol. 9, 2007.

BRILLAT, Régis. Les techniques normatives et juridictionnelles de protection International des droits sociaux. En: L'effectivité de la protection internationale des droits sociaux. Dossier documentaire $42 \mathrm{e}$ session annuelle d'enseignement. Institut International des Droits de I`Homme. Strasbourg, 2011.

CANCADO TRINDADE, Antonio Augusto. El sistema interamericano de protección de los derechos humanos (1948-2000). En: GómEZ ISA, Felipe; PUREZA, José Manuel. La protección internacional de los derechos humanos en los albores del siglo XXI. Humanitarian Net. Universidad de Bilbao. Bilbao, 2004. 
CANCADO TRINDADE, Antonio Augusto. The justiciability of civil rights in the social field, the indirect justiciability of social rights. En: L'effectivité de la protection internationale des droits sociaux. Dossier documentaire 42 e session annuelle d'enseignement. Institut International des Droits de I'Homme. Strasbourg, 2011.

Cancado tRindade, Antonio Augusto; González Volio, Lorena (comps.). La protección internacional de los derechos económicos, sociales y culturales. En: Estudios de Derechos Humanos. Tomo I. Instituto Interamericano de Derechos Humanos. Costa Rica, 1995.

costa, Jean-Paul. La Déclaration universelle des droits de I'homme. Les droits économiques, sociaux et culturels en question. Reporte presentado por el presidente de la Corte Europea de Derechos Humanos el 16 de octubre de 2008. Disponible en: http://www.echr. coe.int/NR/rdonlyres/42BD71A1-099A4B88-B907-185CFF3B3968/0/2008_Strasbourg_colloque_d\%C3\%A9claration_universelle_16_10.pdf

díAz baRRado, C. M. La Carta Social Europea: un instrumento válido para el desarrollo de los derechos sociales en Europa. En: MARIÑO MEnÉndez, F. M. y fernández LIeSA, C. Política social internacional y europea. Universidad Carlos III, Instituto Francisco de Vitoria, Cátedra Concepción Arenal, Ministerio de Trabajo y Asuntos Sociales, Madrid, 1996.

Gómez, Verónica. Economic, Social and Cultural Rights in the Inter-American System. En: Economic, Social and Cultural Rights in Action. Oxford University Press. 2007.
JIMENA QUESADA, Luis. Les systèmes conventionnels de réclamations collectives: la pratique du Comité Européen des Droits Sociaux. En: L'effectivité de la protection internationale des droits sociaux. Dossier documentaire 42e session annuelle d'enseignement. Institut International des Droits de I'Homme. Strasbourg, 2011.

косн, Ida Elisabeth. Economic, Social and Cultural Rights as Components in Civil and Political Rights: A Hermeneutic Perspective. En: The International Journal of Human Rights, Vol. 10, No. 4, pp. 405-430. Diciembre de 2006.

MELISH, Tara J. Rethinking the "LESS AS MORE" Thesis: Supranational Litigation of Economic, Social and Cultural Rights in the Americas. International Law and Politics. Vol. 39, 2007, p. 171.

QUINN, Gerard. "The legal status of the European Social Charter - Taking Interdependence and Indivisibility seriously". UNIDEM Seminar: "The status of International Treaties of Human Rights", octubre 2005.

SUDRE, F. “Le Protocole additionnel à la Charte Sociale Européenne prévoyant un système de réclamations collectives". Revue Générale de Droit International Public, 100, 1996, 3.

TORO HUERTA, Mauricio Ivándel. El fenómeno del soft law y las nuevas perspectivas del derecho internacional. Curso DIP. 2007. UMAG. 
Documentos legales

\section{Convenciones, tratados y protocolos}

\section{Sistema Europeo de Derechos Humanos}

Convenio Europeo para la protección de los Derechos Humanos y de las Libertades Fundamentales (Convención Europea de Derechos Humanos), adoptada por el Consejo de Europa el 4 de noviembre de 1950.

Carta Social Europea, firmada en Turín en 1961.

\section{Sistema Interamericano de Derechos Humanos}

Convención Americana sobre Derechos Humanos (Pacto de San José), suscrita en la Conferencia especializada Interamericana sobre Derechos Humanos. San José, Costa Rica, 7 - 22 de noviembre de 1969.

Protocolo Adicional a la Convención Americana sobre Derechos Humanos en materia de Derechos Económicos, Sociales y Culturales (Protocolo de San Salvador), suscrito en 1988.

Carta de la Organización de los Estados Americanos.

\section{Casos legales citados}

\section{Corte Europea de Derechos Humanos}

\section{Casos contenciosos}

Corte Europea de Derechos Humanos. Caso Muñoz Díaz v. España. Decisión de fondo. Diciembre 8 de 2009.
Corte Europea de Derechos Humanos. Caso Andrejeva v. Letonia. Decisión de fondo. Febrero 18 de 2009.

Corte Europea de Derechos Humanos. Caso Demir y Baykara v. Turquía. Decisión de fondo. Noviembre 12 de 2008.

Corte Europea de Derechos Humanos. Caso Karner v. Austria. Decisión de fondo. Octubre 24 de 2003.

Corte Europea de Derechos Humanos. Caso Pretty v. Reino Unido. Decisión de fondo. Abril 29 de 2002.

Corte Europea de Derechos Humanos. Caso O’Rourke v. Reino Unido. Decisión de admisibilidad. Junio 26 de 2001.

Corte Europea de Derechos Humanos. Caso Z y Otros v. Reino Unido. Decisión de fondo. Mayo 10 de 2001.

Corte Europea de Derechos Humanos. Caso Thlimmenos v. Grecia. Decisión de fondo. Abril 6 de 2000.

Corte Europea de Derechos Humanos. Caso D. v. Reino Unido. Decisión de fondo. Abril 21 de 1997.

Corte Europea de Derechos Humanos. Caso Airey v. Irlanda. Decisión de fondo. Octubre 9 de 1979. 


\section{Comité Europeo de Derechos Sociales}

\section{Reclamaciones colectivas}

Comité Europeo de Derechos Sociales. COHRE V. Francia. Reclamación 63/2010.

Comité Europeo de Derechos Sociales. COHRE V. Italia. Reclamación 58/2009.

Comité Europeo de Derechos Sociales. INTERIGHTS v. Croacia. Reclamación 45/2007.

Comité Europeo de Derechos Sociales. Centro de Defensa de Personas con Discapacidad Mental v. Bulgaria. Reclamación 41 de 2007.

Comité Europeo de Derechos Sociales. Organización Mundial v. la Tortura (омст) v. Irlanda. Reclamación no. 18 de 2003.

Comité Europeo de Derechos Sociales. AutismoEuropa v. Francia. Reclamación 13/2002.

Comité Europeo de Derechos Sociales. Tehy y STTK v. Finlandia. Reclamación 10/2000.

Comité Europeo de Derechos Sociales. Syndicat national des professions du tourisme v. Francia. Reclamación 6/1999.

\section{Corte Interamericana de Derechos Humanos}

\section{Casos contenciosos}

Corte IDH. Caso Pueblo Indígena Kichwa de Sarayaku vs. Ecuador. Fondo y Reparaciones. Sentencia de 27 de junio de 2012.
Corte IDH. Caso Acevedo Buendía y otros ("Cesantes y Jubilados de la Contraloría") vs. Perú. Excepción preliminar, Fondo, Reparaciones y Costas. Sentencia de 1 de julio de 2009, Serie C nº 198.

Corte IDH. Caso del Pueblo Saramaka. vs. Surinam. Excepciones preliminares, Fondo, Reparaciones y Costas. Sentencia de 28 de noviembre de 2007. Serie C nº 172

Corte IDH. Caso Albán Cornejo y otros. vs. Ecuador. Fondo Reparaciones y Costas. Sentencia de 22 de noviembre de 2007. Serie C nº 171.

Corte IDH. Caso Ximenes Lopes vs. Brasil. Sentencia de 4 de julio de 2006. Serie C nº 149.

Corte IDH. Caso Acevedo Jaramillo y Otros vs. Perú. Excepciones preliminares, Fondo, Reparaciones y Costas. Sentencia de 7 de febrero de 2006.

Corte IDH. Caso de la Masacre de Mapiripán vs. Colombia. Sentencia de 15 de septiembre de 2005. Serie C n. 134.

Corte IDH. Caso Niñas Yean y Bosico vs. República Dominicana. Fondo, Reparaciones y Costas. Sentencia de 8 de septiembre de 2005.

Corte IDH: Caso Comunidad Indígena Yakye Axa vs. Paraguay. Fondo Reparaciones y Costas. Sentencia 17 de junio de 2005. Serie C nº. 125.

Corte IDH. Caso Instituto de Reeducación del Menor vs. Paraguay. Excepciones preliminares, 
Fondo, Reparaciones y Costas. Sentencia de 2 de septiembre de 2004.

Corte IDH. Caso Myrna Mack Chang vs. Guatema-

la. Fondo, Reparaciones y Costas. Sentencia de 25 de noviembre de 2003. Serie $C n^{\circ} .101$.

Corte IDH. Caso Bulacio vs. Argentina. Sentencia de 18 de Septiembre de 2003. Serie C nº. 100.

Corte IDH. Caso Cinco Pensionistas vs. Perú. Fondo, Reparaciones y Costas. Sentencia de 28 de febrero de 2003. Serie C $n^{\circ} .98$.

Corte IDH Caso de la Comunidad Mayagna (Sumo) Awas Tingni vs. Nicaragua. Fondo, Reparaciones y Costas. Sentencia de 31 de agosto de 2001. Serie C n. 79.

Corte IDH. Caso Baena Ricardo vs. Panamá. Fondo, Reparaciones y Costas. Sentencia de 2 de febrero de 2001.

Corte IDH. Caso de los "Niños de la Calle" (Villagrán Morales y otros) vs. Guatemala. Sentencia de 19 de noviembre de 1999. Serie $C n^{\circ}$. 63.

\section{Opiniones consultivas}

Corte IDH. "Otros Tratados" Objeto de la Función Consultiva de la Corte (art. 64 Convención Americana sobre Derechos Humanos). Opinión Consultiva OC-1/82 del 24 de septiembre de 1982. Serie A n ${ }^{\circ} .1$.

\section{Comisión Interamericana de Derechos Humanos}

CIDH. Informe anual de la Comisión Interamericana de Derechos Humanos 2011.

CIDH. Observaciones Generales sobre el sistema de informes del artículo 19 del Protocolo de San Salvador. Octubre 5 de 2007.

CIDH. Informe No. 167/11. Petición 12.077. Inadmisibilidad. Joffré Fernández Valdivieso y otros v. Perú. 2 de noviembre de 2011.

CIDH. Informe n. 38/09. Caso12.670. Admisibilidad y fondo. Asociación Nacional de Ex-Servidores del Instituto Peruano de Seguridad Social y otros v. Perú. 27 de marzo de 2009.

CIDH. Informe $\mathrm{n}^{\circ}$. 100/2001. Caso 11.381. Milton García Fajardo y otros v. Nicaragua. 11 de octubre de 2001. 